\title{
MODELAGEM DE DESMATAMENTO E EMISSÕES DE GASES DE EFEITO ESTUFA NA REGIÃO SOB INFLUÊNCIA DA RODOVIA MANAUS-PORTO VELHO (BR-319)
}

\author{
PHILIP MARTIN FEARNSIDE ${ }^{1}$ PAULO MAURÍCIO LIMA DE ALENCASTRO GRAÇA ${ }^{1}$ EDWIN \\ WILLEM HERMANUS KEIZER ${ }^{1,2}$ FRANCISCO DARÍO MALDONADO ${ }^{1,3}$ REINALDO IMBROZIO \\ BARBOSA $^{1}$ E EULER MELO NOGUEIRA $^{1}$
}

\author{
${ }^{1}$ Instituto Nacional de Pesquisas da Amazônia (INPA), Manaus, Amazonas, Brasil \\ ${ }^{2}$ Endereço atual: Greenpeace, Manaus, Amazonas, Brasil, \\ ${ }^{3}$ Endereço atual: Fundação de Ciência, Aplicações e Tecnologia Espaciais (FUNCATE), São José dos \\ Campos, São Paulo, Brasil. \\ pmfearn@inpa.gov.br; pmlag@inpa.gov.br; ekeizer@amazon.greenpeace.org; francisco.dario.maldonado@ \\ gmail.com; reinaldo@inpa.gov.br; euler@inpa.gov.br
}

Recebido Março 2008 - Aceito Maio 2009

\begin{abstract}
RESUMO
Uma simulação de desmatamento e emissões de gases de efeito estufa no período 2007-2050 foi executada para a Área sob Limitação Administrativa Provisória (ALAP) ao longo da rota da Rodovia BR-319 (Manaus-Porto Velho); uma área de $153.995 \mathrm{~km}^{2}$ que representa aproximadamente $10 \%$ do estado do Amazonas. O governo federal, por meio do Ministério dos Transportes, anunciou a sua intenção de reconstruir e pavimentar a Rodovia BR-319, que está abandonada desde 1988. A Secretaria de Estado do Meio Ambiente e Desenvolvimento Sustentável (SDS), do Governo do Estado do Amazonas, e o Ministério do Meio Ambiente (MMA) têm planos para criar uma série de áreas protegidas dentro da ALAP. Nossa simulação compara cenários com e sem as reservas de proteção propostas. A reconstrução e a pavimentação da rodovia são presumidas a serem finalizadas em 2011, com a abertura de estradas laterais associadas em datas especificadas ao longo do período 20142024. A simulação de desmatamento acopla os programas computacionais DINAMICA e Vensim, e incorpora uma série de inovações para permitir que o total de desmatamento responda à melhoria do acesso por estradas, baseado em uma parametrização da relação entre desmatamento e expansão viária observada em imagens de satélite de uma área no noroeste de Rondônia, adjacente à ALAP. A expansão modelada de estradas endógenas não está limitada por uma presunção de um processo de desmatamento puramente "dirigido pela demanda". Esta suposição impediu que outros modelos de desmatamento na Amazônia, representassem o efeito sobre o desmatamento total causado por decisões relativas às reservas (visto que o desmatamento total especificado externamente, baseado na demanda, implica em um "vazamento" de $100 \%$ de qualquer benefício de criação de reservas). A mesma limitação se aplica ao efeito de estradas em modelos dirigidos por demanda. Os resultados obtidos pelo nosso modelo foram validados a partir de uma simulação de desmatamento em Santo Antônio do Matupi, que fica situado adjacente à ALAP, no sul do Amazonas.

A biomassa florestal na ALAP foi calculada a partir de 306 parcelas de um hectare dos levantamentos do Projeto RADAMBRASIL, em 13 tipos florestais identificados, e incorpora uma série de melhorias recentes na metodologia para a obtenção da estimativa. Estimativas das emissões incluem adições para o efeito de liberações de gases-traço de queimadas e de decomposição, e deduções para carbono seqüestrado pelo recrescimento da vegetação na paisagem de equilíbrio que substitui a floresta. As estimativas de emissões estão restritas à biomassa (fitomassa). O carbono do solo foi excluído. Em um cenário "business-as-usual" para a ALAP com apenas as reservas já existentes em 2007, a simulação indica 5,1 milhões de hectares desmatados até 2050 (33\% da ALAP), com uma liberação conseqüente de $0,95 \mathrm{Gt}$ (giga toneladas $=\mathrm{Gt}$, correspondente a um bilhão de toneladas) de carbono equivalente ao carbono de $\mathrm{CO}_{2}\left(\mathrm{CO}_{2}\right.$-equivalente). Em um "cenário de conservação" com as reservas de proteção existentes e propostas, o desmatamento alcança 3,4 milhões de hectares até 2050 (22\% da ALAP), liberando $0,64 \mathrm{Gt}$ de carbono $\mathrm{CO}_{2}$-equivalente. $\mathrm{O}$ efeito das reservas propostas produz uma redução
\end{abstract}


de desmatamento de 1,6 milhões de hectares e de $0,31 \mathrm{Gt}$ de carbono $\mathrm{CO}_{2}$-equivalente em emissões de gases de efeito estufa. Como exemplificação do valor potencial desta redução, se o carbono fosse avaliado a US\$10 por tonelada, esta redução em emissões equivaleria a US\$3,1 bilhões. Como em qualquer simulação, estes resultados dependem de uma série de presunções relativas ao comportamento do desmatamento. Neste caso, largamente influenciado pelas áreas de pequenos agricultores nas quais nosso modelo foi calibrado. Futuras melhorias para melhor representar os papéis dos grandes atores (legais e ilegais), podem resultar em desmatamento mais rápido nas áreas desprotegidas.

Palavras-chave: Amazônia, Carbono, Unidades de Conservação, Rodovias

ABSTRACT: MODELING OF DEFORESTATION AND GREENHOUSE-GAS EMISSIONS IN THE AREA OF INFLUENCE OF THE MANAUS-PORTO VELHO (BR-319) HIGHWAY. A simulation of deforestation and greenhouse-gas emissions over the 2007-2050 period was performed for the Area of Provisional Administrative Limitation (ALAP) along the BR-319 (Manaus-Porto Velho) Highway route, the $153,995-\mathrm{km}^{2}$ area that represents approximately $10 \%$ of the state of Amazonas. The federal Ministry of Transportation has announced its intention of reconstructing and paving the BR-319 Highway, which has been abandoned since 1988. The Amazonas state government's State Secretariat for the Environment and Sustainable Development (SDS) and the federal government's Ministry of Environment (MMA) have plans for creating a series of protected areas within the ALAP. Our simulation compares scenarios with and without the proposed reserves. The highway reconstruction and paving is assumed to be complete by 2011, and associated side roads are opened at specified dates over the 2014-2024 period. The deforestation simulation couples the DINAMICA and Vensim software packages and incorporates a series of innovations to allow the deforestation total to respond to improved road access based on parameterization of the relation between deforestation and the expansion of an access road network observed in satellite imagery of an area in northwest Rondônia that is adjacent to the ALAP. The modeled expansion of endogenous roads is not limited by the assumption of a purely "demand driven" deforestation process. This assumption has prevented other models of Amazonian deforestation from representing the effect on total deforestation caused by decisions regarding reserves because an externally specified deforestation total based on demand implies 100\% "leakage" of any reserve benefits. The same limitation applies to the effect of roads in demand-driven models. Some validation of our overall deforestation results is provided by simulation of deforestation in Santo Antônio do Matupi, which is located adjacent to the ALAP in southern Amazonas.

Florest biomass in the ALAP was estimated based on 306 one-hectare plots from the RADAMBRASIL surveys in 13 identified forest types and incorporates a series of recent improvements in estimation methodology. Emissions estimates include additions for the effect of trace-gas releases from burning and decomposition and deductions for carbon sequestered in regrowth in the equilibrium landscape that replaces forest. Emissions estimates are restricted to biomass (soil carbon is excluded). In a "businessas-usual" scenario for the ALAP with only the reserves that already existed in 2007, the simulation indicates 5.1 million ha deforested by 2050 (33\% of the ALAP), with a consequent release of 0.95 billion tons (gigatons $=\mathrm{Gt}$ ) of $\mathrm{CO}_{2}$-equivalent carbon. In a "conservation scenario" with both existing and proposed reserves, deforestation reaches 3.4 million ha by 2050 ( $22 \%$ of the ALAP), releasing 0.64 $\mathrm{Gt}$ of $\mathrm{CO}_{2}$-equivalent carbon. The effect of the proposed reserves is a reduction of deforestation by 1.6 million ha and of greenhouse-gas emissions by $0.31 \mathrm{Gt} \mathrm{CO}_{2}$-equivalent carbon. As an illustration of the potential scale of the value of this reduction, if carbon were valued at US\$10/ton this reduction in emissions would be worth US\$3.1 billion. As in any simulation, these results depend on a series of assumptions regarding deforestation behavior, in this case largely influenced by the small-farmer areas in which our model was calibrated. Future improvements to better represent the roles of large actors, both legal and illegal, may well result in more rapid clearing of unprotected areas.

Keywords: Amazonia, Carbon, Conservation Units, Global Warming 


\section{INTRODUÇÃO}

A principal contribuição brasileira ao aquecimento global é o desmatamento amazônico (Brasil, MCT, 2004). Modelar esse processo, portanto, representa uma alta prioridade para subsidiar a tomada de medidas visando diminuir essa emissão, inclusive por meio do aproveitamento do valor da Redução de Emissões por Desmatamento e Degradação (REDD), que é um dos pontos chaves nas negociações sob a Convenção de Clima atualmente. Este estudo apresenta simulações de desmatamento e de emissões de gases de efeito estufa em uma área no estado do Amazonas, onde se espera nas próximas décadas grandes reduções na cobertura florestal, em decorrência da construção da infra-estrutura planejada (Figura 1). Essa área corresponde a "Área sob Limitação Administrativa Provisória" (ALAP), de $153.995 \mathrm{~km}^{2}$, ao longo da Rodovia BR-319, que corta o Estado de norte a sul, unindo Manaus (Amazonas) e Porto Velho (Rondônia). Essa rodovia está abandonada desde 1988, quando o serviço de ônibus entre Manaus e Porto Velho cessou, entretanto, a reconstrução da estrada até 2011 foi anunciada recentemente pelo governo federal como parte do Plano de Aceleração do Crescimento (PAC).

Rondônia e Amazonas contrastam nitidamente em termos de desmatamento (Figura 2). As florestas ao redor de Manaus estão em grande parte intactas e o desmatamento está acontecendo em um ritmo relativamente lento, enquanto o estado de Rondônia foi quase completamente desmatado exceto

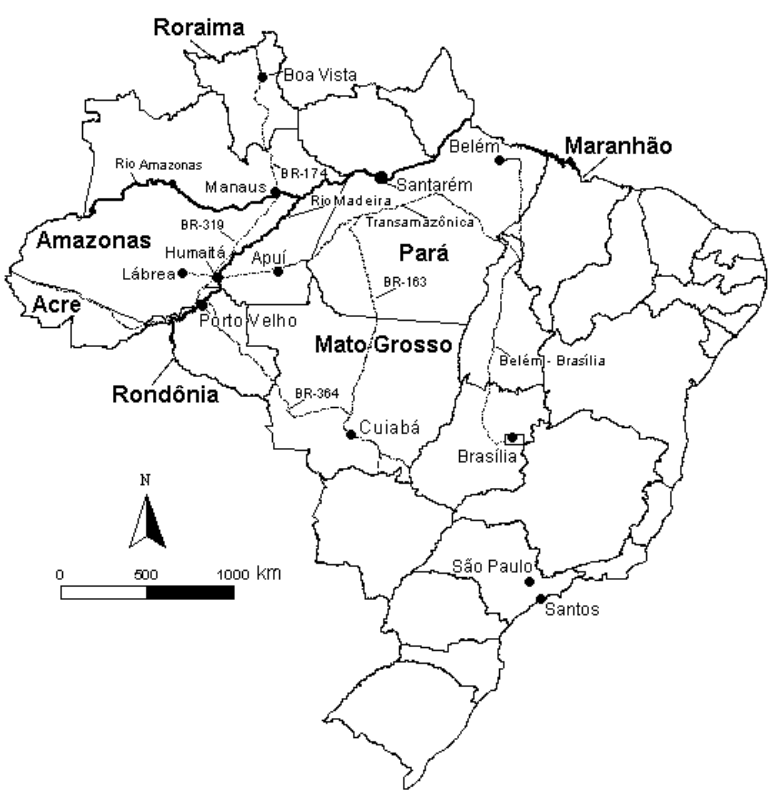

Figura 1 - Mapa do Brasil com as principais rodovias amazônicas existentes e planejadas, inclusive a BR-319 (Manaus-Porto Velho) Fonte: Fearnside \& Graça, 2006. em áreas de terras indígenas e unidades de conservação, tais como parques nacionais e reservas biológicas. Rondônia é a principal fonte de migrantes que se deslocam para outras áreas no sudoeste da Amazônia, tais como o estado do Acre e a parte sul do Amazonas. Desde o período em que a Rodovia BR-319 foi abandonada (1988), Rondônia é fonte de migração para áreas circunvizinhas. Esse movimento aumentou continuamente, como é evidente na recente expansão do desmatamento em partes acessíveis do sul do Amazonas, tais como Apuí, Santo Antônio do Matupi, Humaitá, Lábrea e Boca do Acre (veja Brasil, INPE, 2007). Portanto, é razoável deduzir, sem depender de resultados de modelagem, que a reconstrução da rodovia, hoje, reativaria uma pressão maior para o desmatamento do que em relação ao período 1974-1988, quando a rodovia permaneceu aberta.

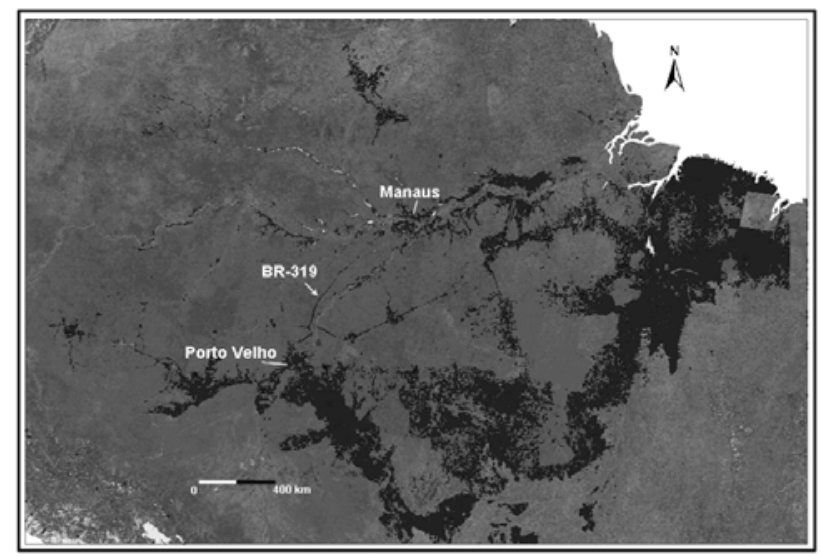

Figura 2 - Desmatamento na Amazônia brasileira até 2006, baseado em dados do programa PRODES do Instituto Nacional de Pesquisas Espaciais (INPE) (desmatamento em preto) (dados de: Brasil, INPE, 2007). Em destaque a rodovia BR-319, ainda com grande parte da cobertura floresta intacta ao redor do seu traçado.

Estradas laterais planejadas conectariam a rodovia principal a todas as sedes municipais ao longo dos rios Madeira e Purus, provendo áreas substancialmente grandes ao desmatamento, além de expansão do desmatamento a partir das margens da própria Rodovia BR-319. Estas estradas laterais não fazem parte do Plano de Aceleração do Crescimento, mas são aguardadas pelos municípios interessados desde 1997 (A Crítica, 1997). É provável que a pressão política para a construção delas seja irresistível depois que a rodovia principal esteja aberta, e esta pode ser adotada como premissa na construção de cenários modelados. As estradas laterais possibilitarão o acesso à maior parte do interflúvio Madeira-Purus, que é o mais estreito dos interflúvios entre os afluentes do rio Amazonas e que abriga um número extraordinariamente grande de espécies biológicas endêmicas. Além de abrir este interflúvio ao desmatamento, 
uma das estradas laterais está planejada para cruzar o rio Purus em Tapauá e continuar até Coari, Tefé e Juruá, assim tornando acessível o grande bloco de floresta intacta que ocupa a parte ocidental do estado do Amazonas (Fearnside \& Graça, 2006). Isto transformaria a geografia do desmatamento na Amazônia como um todo, onde aproximadamente $80 \%$ da atividade de desmatamento têm sido restrita ao "arco de desmatamento", localizado nas periferias sul e leste da floresta, enquanto as grandes extensões de floresta na Amazônia ocidental permaneceram intactas devido à falta de acesso por estrada.

A Rodovia BR-319 teria dois impactos importantes, como indicado pelo histórico de outras obras de infra-estrutura na Amazônia. Um deles seria a expansão do desmatamento a partir das margens da rodovia e das estradas laterais associadas (Figura 3). O outro seria facilitar a migração de uma ponta da rodovia até a outra, criando um fluxo de população de Rondônia para Manaus. Ao chegar a Manaus, parte desta população ficaria na cidade, parte ocuparia a área rural circunvizinha, por exemplo, o Distrito Agropecuário da Zona Franca de Manaus (SUFRAMA), e parte continuaria pela Rodovia BR174, já pavimentada, até novas fronteiras de desmatamento em Roraima. Neste último caso, incrementariam as altas taxas de desmatamento já existentes ao longo de todo o setor sul da BR 174 (Barbosa et al., 2008). O potencial para tal migração é significativo. É provável que um grande pulso aconteça em 2013, ao término da construção das barragens hidrelétricas de Santo Antônio e Jirau no Rio Madeira, em Rondônia. Os projetos de construção das barragens terão um total de 20.000 trabalhadores, atraídos de todas as partes do Brasil, que serão dispensados quase simultaneamente quando as represas estiverem construídas. É improvável que esta população de trabalhadores desempregados

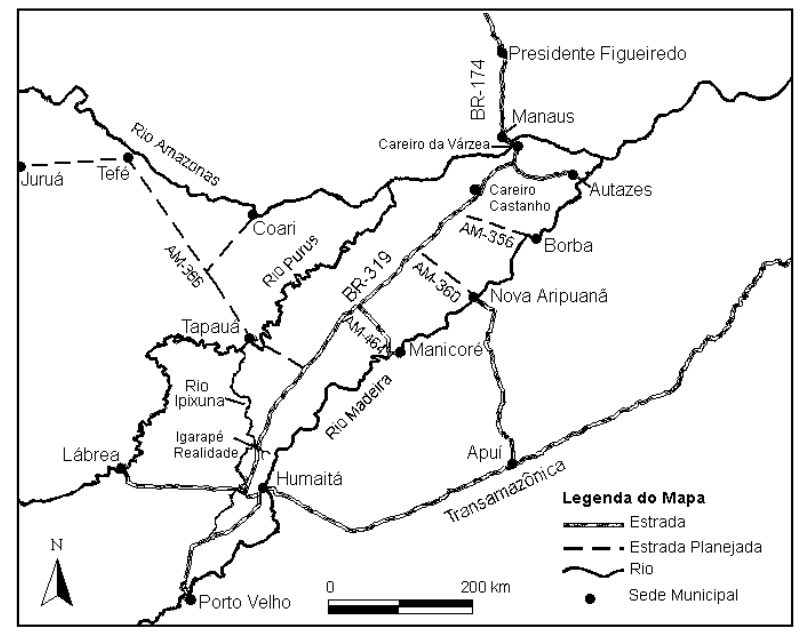

Figura 3 - A Rodovia BR-319 e estradas laterais propostas Fonte: Fearnside \& Graça, 2006. permaneça em Porto Velho, sendo que uma estrada asfaltada com serviço de ônibus até Manaus fará com que a migração para a Amazônia central seja a opção mais atraente.

\section{DESAFIOS PARA MODELAR O DESMATAMENTO}

\subsection{Cenário de linha-base}

Como o desmatamento deve ser modelado depende fortemente do propósito das estimativas resultantes. Pretende-se que as estimativas do atual estudo sirvam como uma maneira de quantificar as implicações ambientais de diferentes possíveis decisões de desenvolvimento, tais como a construção de rodovias e a criação de áreas protegidas. Cenários com e sem as rodovias ou reservas servem como base para comparações. Diferenças nas áreas de floresta perdidas e diferenças em impactos como as emissões de gases de efeito estufa, provêem medidas quantitativas dos custos e benefícios ambientais de diferentes opções de política.

A obtenção de crédito de carbono sob o Protocolo de Kyoto torna-se possível, presumindo que reduzir o desmatamento ficará elegível para crédito sob o Mecanismo de Desenvolvimento Limpo no Segundo Período de Compromisso do Protocolo (2013-2017). É provável, que o cálculo do benefício de carbono seja com base no critério de "adicionalidade", ou seja, o cálculo de emissões evitadas que estão além do que teria sido emitido na ausência de um projeto de mitigação dentro do Protocolo de Kyoto (Artigo 12). Isto envolve a comparação do resultado de um determinado projeto observado com um cenário de linha-base hipotético, que representa o que teria acontecido sem o projeto. Há duas possíveis abordagens para construir o cenário de linha-base. Uma delas consiste em fazer uma extrapolação simples das tendências passadas, refletindo a série histórica de estimativas de desmatamento na área do projeto, baseado em imagens de satélite. Cálculos deste tipo ("linha-base histórica"), também conhecido como "reduções compensadas", têm uma atração forte porque não podem ser manipulados para exagerar os benefícios de um projeto. Porém, somente sob circunstâncias especiais vai fornecer uma aproximação razoável do resultado intencionado como representação daquilo que teria sido emitido na ausência do projeto de mitigação. A situação sob a qual a linha-base histórica funcionaria bem é aquela cujo desmatamento foi procedido rapidamente durante algum tempo e uma quantidade significante de floresta permanece em pé e disponível para desmatar. Se uma ampla provisão de floresta não for disponível a taxa de desmatamento necessariamente diminuirá mesmo sem um projeto de mitigação, portanto, significando que a linha-base histórica gerará apenas "ar quente", ou crédito de carbono sem real benefício climático. 
A outra situação na qual a linha-base histórica não funcionará como planejada é onde muito pouco desmatamento aconteceu no passado, mas um desenvolvimento novo, por exemplo, a abertura de uma rodovia, implica em desmatamento significativo no futuro. Aqui a linha-base histórica não gerará nenhum crédito de carbono, porque é impossível reduzir a taxa de desmatamento a um nível abaixo de zero, e qualquer taxa de desmatamento possível sob as condições futuras seria mais alta do que a desprezível taxa histórica. Esta é a situação aplicada às áreas selecionadas para o presente estudo: Apuí e a Rodovia BR-319.

A abordagem que pode ser aplicada para reduzir emissões do desmatamento nas áreas de estudo é a simulação de um cenário de referência "Business as Usual" de mudança de uso da terra. Isto tem que representar o processo de desmatamento, que é provável para acontecer sem intervenções ambientais, tais como a criação de áreas protegidas e/ou uma decisão de cancelar ou adiar o projeto rodoviário a favor de um dos outros modos de transporte alternativos, tais como uma estrada de ferro ou um porto novo para transporte de frete via cabotagem para São Paulo (veja Fearnside \& Graça, 2006). Para mostrar aos que concedem crédito que nenhuma manipulação da linha-base aconteceu, o cenário de linha-base deve ser suficientemente transparente, documentado e "conservador" da perspectiva do crédito de carbono (i.e., desmatamento da linha-base não exagerado).

\subsection{Cenários de mitigação}

Qualquer crédito de carbono a ser concedido atualmente por reduzir o desmatamento, terá como base de cálculo as áreas de floresta e estoques de carbono que são observados ou medidos no mundo real depois que um período de atividade de mitigação decorre, e não com base em cenários modelados. Não obstante, cenários que incluem os efeitos de atividades de mitigação podem ser muito úteis aos tomadores de decisão no governo, negociadores de clima e financiadores em potencial de projetos de mitigação. A mudança de uso da terra em períodos futuros precisa ser simulada, tal como o período 2007-2050 considerado no presente estudo, assim incorporando uma gama de possíveis decisões relativas à infra-estrutura, áreas protegidas e outras possíveis ações de governo.

\section{MODELOS ANTERIORES}

\subsection{Laurance et al. (2001)}

Uma simulação de desmatamento na região da Amazônia Legal Brasileira ao longo do período 2000-2020 foi produzida por Laurance et al. (2001, 2005, Kirby et al., 2003). Esta simulação utilizou a taxa histórica de expansão de desmatamento (e de formas adicionais de perturbação, tais como

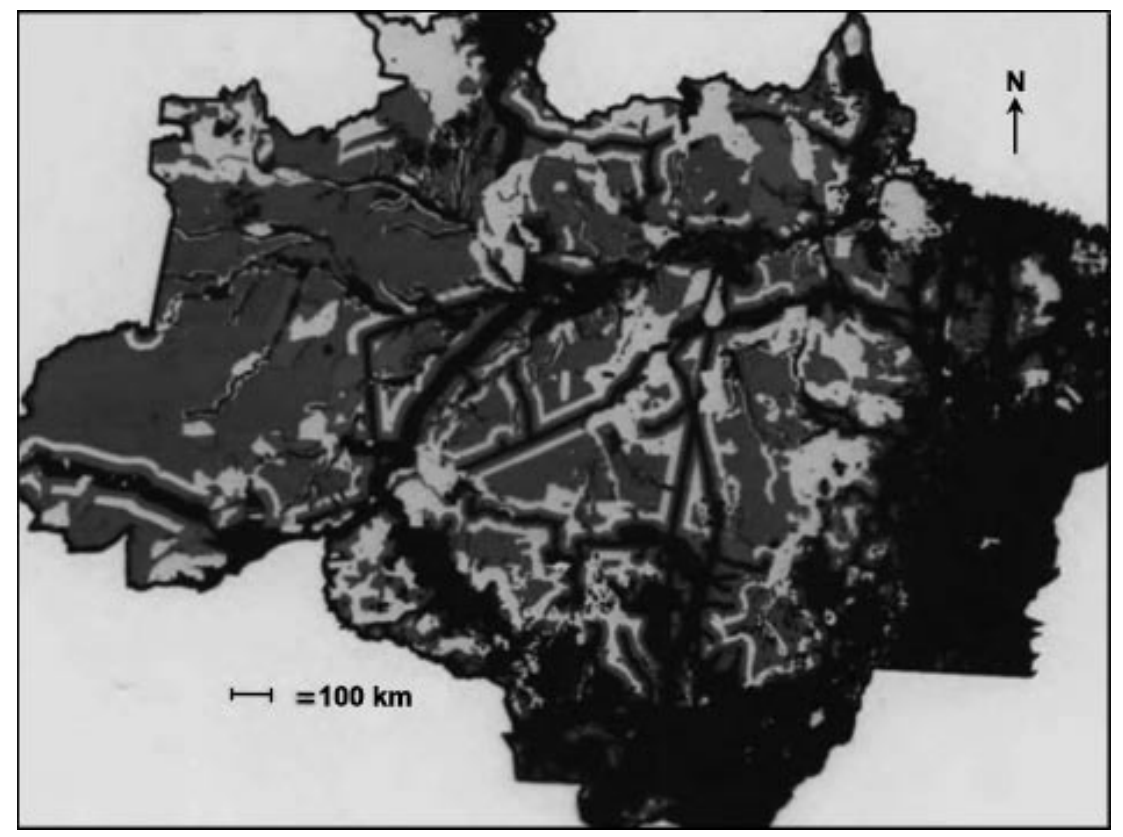

Figura 4 - Laurance et al. (2001) simulação de desmatamento e não-floresta (preto) e perturbação (cinza médio e claro) até 2020 em um "cenário otimista" se a infra-estrutura projetada, especialmente a que foi anunciada sob o programa Avança Brasil (inclusive a Rodovia BR-319) tivesse sido construída em 2000.

Fonte: Laurance et al. (2001). 
a exploração madeireira) em rodovias existentes, para projetar o que aconteceria se as obras de infra-estrutura anunciada sob o Programa "Avança Brasil" de 2001 a 2003 fossem realizadas, inclusive a Rodovia BR-319. O resultado mostrou a rota da Rodovia BR-319 produzindo uma faixa larga de desmatamento, flanqueada por zonas sucessivas de outras perturbações (Figura 4). Estas transições foram representadas em um sistema de informações geográficas (SIG), onde as transições ocorreriam em faixas de território, conhecidas como "áreas de entorno" ou "buffers", que delineiam áreas de terra localizada a diferentes distâncias de feições como estradas pavimentadas e não pavimentadas.

A simulação de Laurance et al. (2001) era uma compilação simples de relações conhecidas, por exemplo, entre proximidade de rodovia e desmatamento, para extrair lições para a política. O sistema de informações geográficas, utilizado no modelo, quantificou os vários efeitos sobrepostos de projetos diferentes e de estimativas derivadas de desmatamento e áreas alteradas, assim como também permitiu uma estimativa grosseira de emissões de gases de efeito estufa. Não foram incluídas as relações causais subseqüentes da expansão do desmatamento. $\mathrm{O}$ modelo inclui o efeito inibidor de várias classes de áreas protegidas. A inclusão de efeitos de áreas protegidas e de formas de perturbação, que não fossem o desmatamento total, representava vantagens significantes, quando comparado a outros modelos desenvolvidos na mesma época (por exemplo, Nepstad et al., 2000, 2001). Na realidade, o efeito das reservas, junto com a escolha de locais como a fonte de dados para o desmatamento histórico, resultou em estimativas mais conservadoras do desmatamento no estudo de Laurance et al. (2001) do que no estudo de Nepstad et al. (2000, 2001) (veja Fearnside, 2002).

Apesar das limitações do modelo de Laurance et al. (2001), este teve como característica importante, não ser "dirigido pela demanda" em sua representação de desmatamento. Isto significa que não só representou onde o desmatamento aconteceria, mas também quanto o desmatamento total seria. Modelos dirigidos pela demanda (como Nepstad et al., 2000; Soares-Filho et al., 2004, 2005, 2006) calculam o desmatamento total separadamente, baseado em suposições que consideram fatores tal como o produto interno bruto (PIB), e então só representa onde o desmatamento acontece. A diferença é importante se o modelo é aplicado para avaliar as conseqüências de decisões individuais de desenvolvimento, tais como, construir uma estrada ou criar uma reserva. No caso de um modelo puramente dirigido pela demanda, a construção de uma estrada não aumentaria o total de desmatamento, e a criação de uma reserva não o diminuiria, porque o total de desmatamento é fixado de antemão sem considerar o efeito dessas ações de política. Isto faz com que o modelo de Laurance et al. (2001) tenha conclusões sobre o total de desmatamento, enquanto outros modelos com muito mais complexidade na sua representação

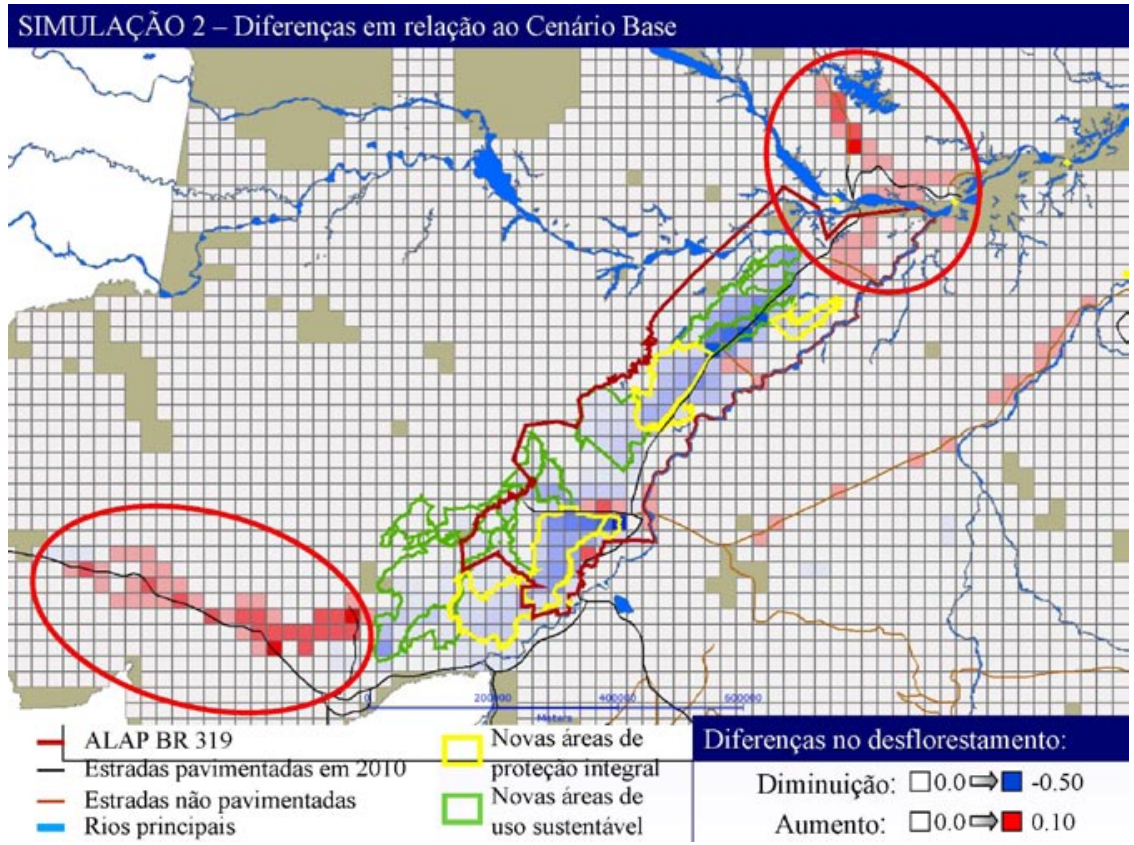

Figura 5 - Efeito de áreas protegidas propostas na BR-319 ALAP indicado pelo deslocamento do desmatamento em outras áreas (indicado pelo círculo vermelho) em uma simulação em CLUE. Porém, este "vazamento" é um artefato do método de simulação que usa um valor externamente especificado pelo total de desmatamento (veja texto).

Fonte: Rede Temática GEOMA, 2006; também veja Câmara, 2007 
espacial, podem apenas indicar a localização e não a quantidade de desmatamento, sendo que a taxa de desmatamento é apenas uma premissa de entrada para os cenários.

\subsection{Aguiar (2006)}

O desmatamento na Amazônia Legal Brasileira foi simulado usando o programa computacional CLUE (Conversion of Land Use and its Effects), desenvolvido pela Universidade de Wageningen, na Holanda (Aguiar, 2006; Aguiar et al., 2007). Uma simulação específica para a área da Rodovia BR-319 também foi executada (Rede Temática GEOMA, 2006; Câmara, 2007). O CLUE produz uma representação de espaço do local de desmatamento baseado em tais fatores como distância até mercados, distância até estradas, qualidade do solo e status como área protegida (Veldkamp et al., 2001; Kok et al, 2001; Verburg et al., 2002). As relações entre o uso da terra e seus fatores determinantes são avaliadas a partir de regressões logísticas. A resolução espacial é bastante grosseira quando áreas extensas são simuladas. Por exemplo, Aguiar (2006) usou um tamanho de célula de grade de $25 \mathrm{~km} \times 25 \mathrm{~km}$. O programa não inclui meios para calcular o total de desmatamento, e isto culmina na presunção de que o desmatamento anual segue uma trajetória fixa, podendo permanecer constante a um determinado nível, aumentando linearmente por uma quantia fixa a cada ano, ou aumentar exponencialmente por uma porcentagem fixa anualmente. Isto limita severamente os propósitos para os quais as simulações podem ser aplicadas. Não podem ser representados os efeitos de decisões de políticas diferentes, como construção de estradas e criação de reservas, porque o desmatamento total anual será o mesmo, ainda que estradas ou reservas sejam criadas, isto só mudará a distribuição espacial do desmatamento, e não a sua extensão total. No jargão que cerca o Protocolo de Kyoto, criar uma reserva resulta em 100\% de "vazamento", ou seja, o desmatamento evitado dentro da área da reserva criada simplesmente seria deslocado para outro local. Isto pode ser visto na Figura 5, onde o desmatamento que teria acontecido nas reservas propostas ao longo da Rodovia de BR-319 aconteceu no Acre, Boca do Acre e na área ao redor de Manaus.

\subsection{Soares-Filho et al. (2006)}

Britaldo Soares-Filho e colaboradores desenvolveram um pacote de software chamado DINAMICA para simular a distribuição espacial do desmatamento (Soares-Filho et al., 2002, 2003; Soares-Filho, 2004). Nas simulações, o programa DINAMICA pode operar junto com a contribuição de uma simulação não-espacial executada no software Vensim (Ventana Systems Inc., 2007). Recentes melhorias no software

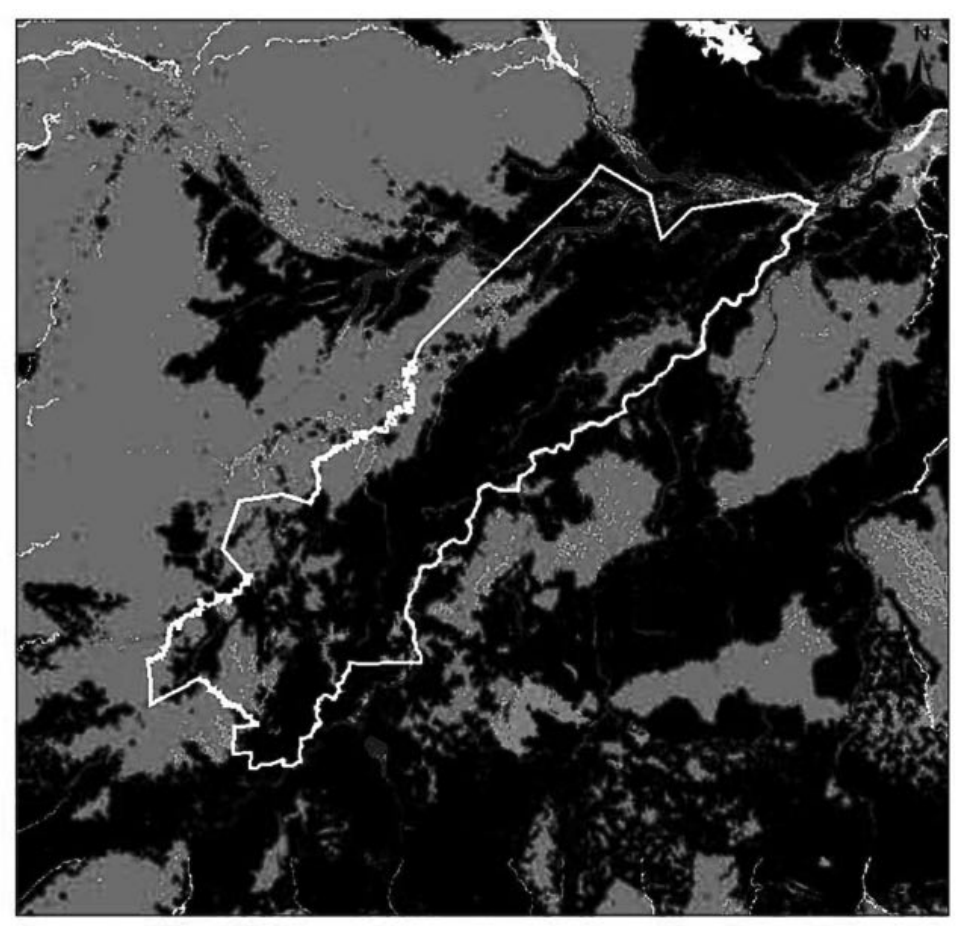

Figura 6 - O cenário de referência ("Business as Usual") de Soares-Filho et al. (2006) indica praticamente o interflúvio Madeira-Purus inteiro sendo desmatado até 2050. A figura destaca o limite da ALAP 319 em branco, o desmatamento está representado em preto e a floresta em nível de cinza médio. 
DINAMICA permitem que cálculos feitos pelo Vensim sejam executados dentro do próprio DINAMICA. Baseado em indicadores econômicos como crescimento do PIB, o programa Vensim calcula o desmatamento total durante cada ano a ser simulado. $\mathrm{O}$ vetor das taxas de desmatamento anuais é passado então ao programa DINAMICA, que determina onde a alocação do desmatamento acontecerá baseada em pesos de evidência, ou na probabilidade relativa que cada célula na grade que representa a paisagem será desflorestada. Estes pesos são derivados de relações calculadas de pares de imagens de satélite das quais são feitos cálculos de probabilidade de desmatar a distâncias diferentes de estradas, considerando a influência da qualidade do solo, a influência de áreas protegidas, distância dos mercados, distância do desmatamento existente e outras características.

O modelo do Vensim usado por Soares-Filho et al. (2006) calcula o vetor de taxas de desmatamento, ou seja, de "demanda" para desmatamento, para o período inteiro da simulação (2001-2050) separadamente do modelo espacial do DINAMICA. Posteriormente, repassa este vetor para que o DINAMICA possa determinar onde este desmatamento ocorre. Não há uma retroalimentação anual entre os dois modelos, que seria necessária para que as características espaciais possam influenciar na taxa de desmatamento no ano seguinte. Portanto, a existência de reservas não muda o total de desmatamento (i.e., o vazamento é de $100 \%$ ). O uso do modelo para o efeito de reservas envolve recortar as áreas das reservas e subtrair o desmatamento contido nelas do total, ou seja, um método de "cookie cutter" (cortador de biscoitos), que efetivamente representa um vazamento zero (i.e., Soares-Filho \& Dietzsch, 2008). O que limita o quanto um fazendeiro desmata e, portanto, o quanto o conjunto de todos os atores desmata no total, normalmente é a capacidade do fazendeiro, ou seja, a oportunidade. Se ele tivesse mais dinheiro, mais mão-de-obra, e menos risco de punição, então ele desmataria mais. Sua opção de desmatar não está diretamente associada à regulação do mercado, com base na lei da oferta e da procura, e sim pela disponibilidade de capital. Isto está exemplificado no histórico de subidas e descidas na taxa de desmatamento amazônico, a qual declinou de 1988 até o ponto baixo em 1991 (recessão no governo de Fernando Collor de Mello) e depois teve um pico em 1995 (seguindo o início do Plano Real), que refletiam a disponibilidade de dinheiro para investimento em desmatamento (i.e., a capacidade dos fazendeiros para desmatar).

O software DINAMICA inclui rotinas para simular a construção de redes de estradas secundárias, e para iniciar focos de desmatamento novos (ao invés da expansão de clareiras já existentes). Estas características fazem o DINAMICA mais complexo do que o CLUE, e permite representar alguns aspectos que são conhecidos do desmatamento no Brasil. Especialmente importantes são a expansão da rede de estradas endógenas
(Souza Jr. et al., 2005) e o processo de estabelecimento de novas fronteiras (Fearnside, 1987).

Simulações com o DINAMICA indicam a rota da Rodovia BR-319, formando um enorme corredor de desmatamento. Praticamente o interflúvio Madeira-Purus inteiro é indicado como desmatado até 2050 (Soares-Filho et al., 2006; veja Figura 6).

As simulações e capacidades dos softwares DINAMICA e Vensim evoluíram continuamente (Soares-Filho et al., 2003, 2004, 2006). Estes proveram séries úteis de representações, de como é provável que o desmatamento se espalhe sob cenários do tipo "Business as Usual". Séries paralelas de cenários de governança representaram o que aconteceria se regulamentos como o Código Florestal de 1965 (Brasil, 1965) fossem respeitados, combinado com uma diminuição do desmatamento total por uma quantidade presumida (por exemplo, Carvalho et al., 2001, 2002; Soares-Filho et al., 2006). Estes estão baseados em suposições relativas à quantidade global de desmatamento, ao invés de ser derivado de cálculos baseados em dados sobre como o comportamento do desmatamento responde a medidas específicas de política. A utilidade de tais cenários de governança está no foco da discussão sobre a necessidade de governança, mas os cenários não deveriam ser confundidos com um cenário "com projeto" para qualquer determinado conjunto de medidas de governança, tais como o Programa "BR-163 Sustentável" (veja: Alencar et al., 2004, 2005) no caso da Rodovia SantarémCuiabá (veja Fearnside, 2007). Diferente dos cenários utilizados no modelo de Soares-Filho et al. (2006), o presente estudo se restringe aos efeitos de estradas e reservas e não oferece cenários de governança.

\subsection{Modelos econométricos e outros}

Outros tipos de modelagem, especialmente modelos econométricos, têm sido aplicados ao desmatamento amazônico. Geralmente estes se aplicam a uma escala maior, representando, por exemplo, a Amazônia brasileira como um todo, sem ser detalhados em termos espaciais. Os dados geralmente vêm de censos ao nível de município, ou então de unidades de censo, do Instituto Brasileiro de Geografia e Estatística (IBGE). Exemplos incluem as equações desenvolvidas por Reis \& Margulis (1991) e Reis \& Guzmán (1994), para associar a taxa de desmatamento com dados sobre população, percentagem de área em cultivos agrícolas, densidade de bovinos por $\mathrm{km}^{2}$, intensidade de exploração madeireira em $\mathrm{m} 3 \mathrm{~km}^{-2}$, comprimento de estradas por $\mathrm{km}^{2}$, distância do capital do estado, e uma variável dummy para representar diferenças entre estados. Nestes modelos, as estradas são consideradas como um determinante significativo do desmatamento. $\mathrm{O}$ custo de transporte, que depende diretamente da disponibilidade e qualidade das estradas, tem mostrado ser a 
chave determinante do desmatamento: uma redução de $20 \%$ no custo de transporte resulta em um aumento no desmatamento na Amazônia de 29-32\% (Cattaneo, 2001, p. 230). Em uma análise por Chomitz \& Thomas (2003) desenhado para testar o efeito da pluviosidade sobre taxas de desmatamento, foi demonstrado que as estradas aumentam o desmatamento, mas a magnitude do aumento depende do controle de outras variáveis, tais como o impacto do desmatamento pré-existente, que tem um efeito mesclado com o das estradas. Análises no nível municipal indicam que estradas aumentam o desmatamento em locais onde muito da floresta permanece intacta (como é o caso na ALAP da Rodovia BR-319), mas em locais onde o processo de desmatamento já está bem avançado a construção de estradas adicionais diminui o desmatamento (Andersen et al., 2002; Reis \& Weinhold, 2004). No entanto, estudos subseqüentes das mesmas bases de dados do IBGE, mas usando dados ao nível de unidades de censo (i.e., com aproximadamente 20 vezes mais dados), indicam que estradas são propulsores do desmatamento em todas as fases do processo (Pfaff et al., 2007).

\section{UM MODELO PARA DESMATAMENTO NA BR-319}

\subsection{Abordagem de simulação com dinamica}

\subsubsection{Modelo conceitual de DINAMICA}

O DINAMICA é um modelo de simulação explicitamente espacial da dinâmica da paisagem, que se baseia em um algoritmo de autônomo celular. Modelos fundamentados em autômatos celulares, tal como o DINAMICA, podem ser entendidos como sistemas de dinâmica espacial, no qual o estado de cada célula dentro de um arranjo espacial (grade de células) depende do estado prévio das células de vizinhança, de acordo com um conjunto de regras de transição estabelecido. Conforme Soares-Filho et al. (2006), autônomos celulares são capazes de simular os padrões espaciais do desmatamento incorporando um mapa de probabilidades representando a influência integrada de dados cartográficos na alocação do desmatamento. O DINAMICA reúne funções de transição baseada na vizinhança multi-escala, conceito de fases utilizando um processo estocástico de simulação em múltiplas etapas, um método de retroalimentação espacial a partir de cálculos de variáveis dinâmicas, uma componente que direciona a expansão da malha viária, e pesos de evidência para calcular as probabilidades de transição da dinâmica espacial. Seu arcabouço também foi concebido para acoplar outros modelos em uma arquitetura multinível constituído de submodelos. $\mathrm{O}$ esquema do arcabouço do DINAMICA ilustrando suas funcionalidades pode ser observado na Figura 7.

Um maior detalhamento das funcionalidades incorporadas no programa DINAMICA pode ser encontrado no site http:// www.csr.ufmg.br/dinamica.

\subsection{Parâmetros para a ALAP BR-319}

\subsubsection{Desenvolvimento do modelo para a ALAP BR- 319}

O modelo foi desenvolvido em dois módulos acoplados, cada um deles executado em software diferente. Um modelo não espacial executado em Vensim 3.0 e um modelo espacial desenvolvido em DINAMICA EGO (versão mais recente do programa), com resolução espacial de $500 \mathrm{~m}$. Estes dois modelos permutam parâmetros em cada ciclo da simulação como se apresenta na Figura 8.

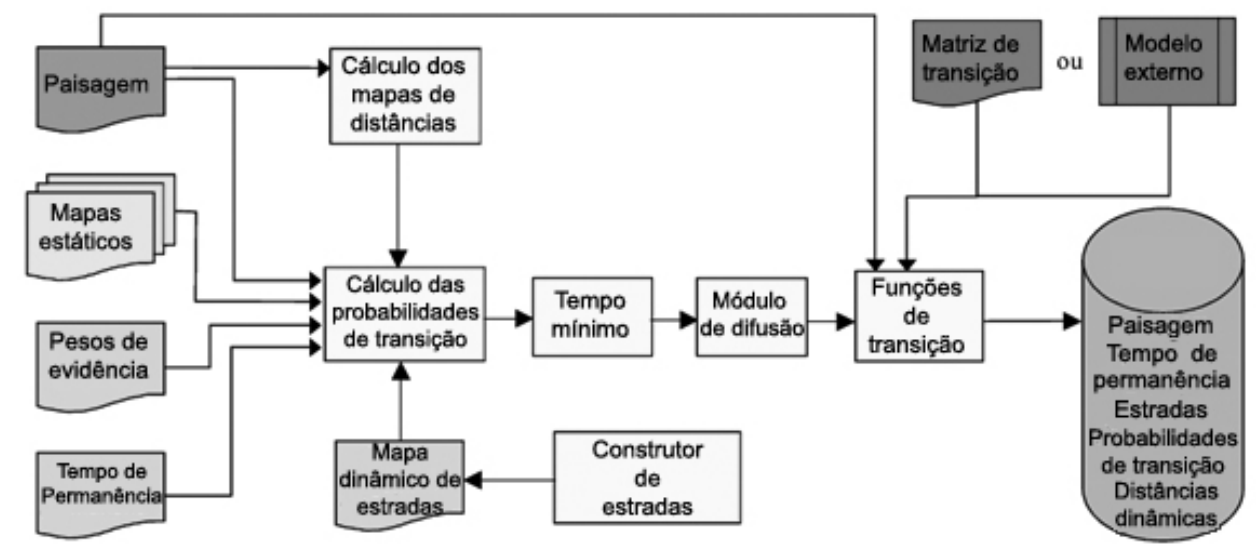

Figura 7 - Fluxograma esquematizando a arquitetura do DINAMICA. Fonte: modificado de http://www.ufmg.br/csr/dinamica, acesso em $13 / 10 / 2007$. 
O modelo Vensim calcula as taxas e as disponibiliza para o modelo espacial DINAMICA EGO. As taxas calculadas são as de desmatamento, "clearing" (corte das capoeiras) e recuperação (regeneração da vegetação). Para o cálculo das taxas o modelo espacial disponibiliza valores quantitativos, que caracterizam a cena, como as superfícies de floresta acessível e fundiária entre outras, e a de extensão de estradas que ainda não tem produzido desmatamento. A Figura 9 apresenta um quadro sintético dos fluxos de informação em cada ciclo.
A primeira linha do diagrama corresponde ao módulo espacial de construção de estradas. Este utiliza os conceitos de atratividade e friç̧ão para seu funcionamento. A atratividade é formada por mapas numéricos onde as áreas propícias para agropecuária possuem os maiores valores, as áreas protegidas ou inundáveis possuem os menores valores e as áreas de proteção integral valor zero. Nos mapas de fricção as áreas com maior declividade, inundadas ou com proteção ambiental, possuem os maiores valores. Desta forma, o módulo aumenta a rede de

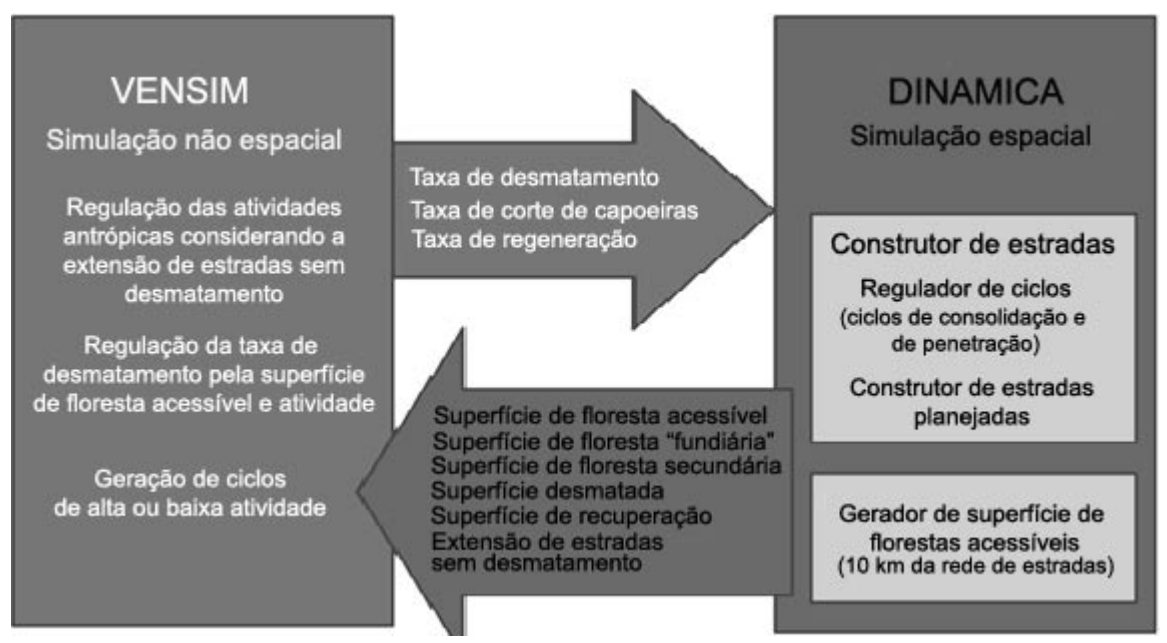

Figura 8 - Acoplamento dos modelos não espacial e espacial. Em cada ciclo são enviadas as variáveis calculadas entre os módulos.

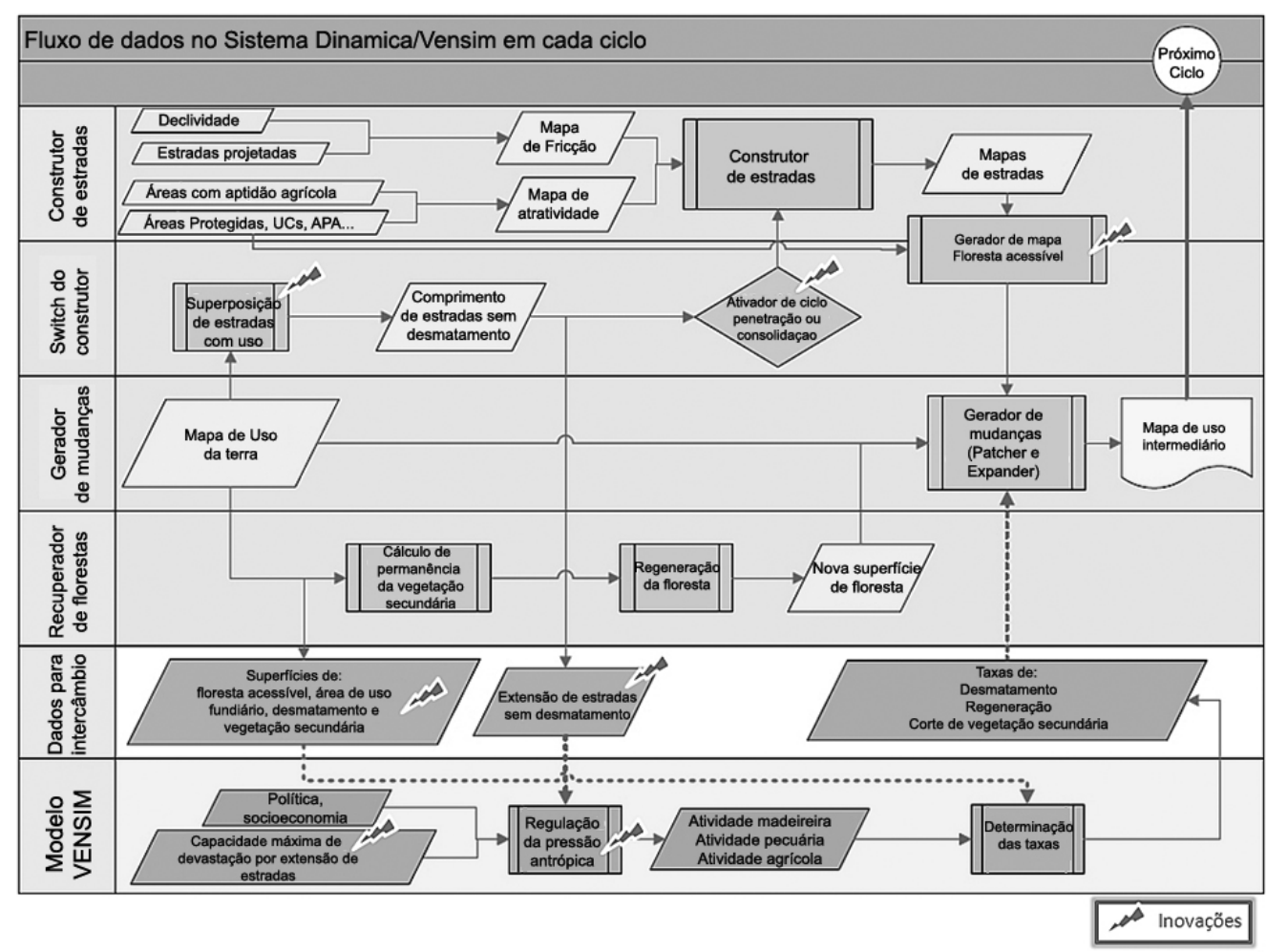

Figura 9 - Diagrama dos fluxos de informação onde são indicadas as inovações desenvolvidas no laboratório de Agroecologia do INPA. 
estradas e disponibiliza o novo mapa para o resto do modelo. Este módulo de construção de estradas pode ter sua atividade regulada em função da superfície de estradas que ainda não tenham produzido desmatamento.

Os mapas de estradas, combinados com os mapas de uso do ciclo anterior, geram mapas de floresta disponível sobre os quais são aplicadas as taxas fornecidas pelo módulo não espacial (Vensim). Esta superfície de floresta disponível é uma das principais inovações deste modelo espacial. Esta superfície está estreitamente relacionada com o desenvolvimento da rede de estradas, e com a localização de áreas de proteção ambiental, como veremos no ponto seguinte. A floresta disponível é uma faixa de floresta a $10 \mathrm{~km}$ de distância das estradas. Dentro desta faixa se encontra a faixa de floresta fundiária (florestas disponíveis em uma propriedade padrão tal como aquelas oriundas de assentamentos antigos do INCRA na BR-319), relacionada com a propriedade de pequena ocupação.

$\mathrm{O}$ cálculo das taxas para desmatamento, clearing e recuperação está relacionado com a superfície fundiária, uma faixa de $2 \mathrm{~km}$ de distância da estrada. A área de floresta dentro desta faixa modifica a atividade agropecuária. Na esquerda da Figura 10 observa-se a série de variáveis de superfície, que o modelo espacial envia ao modelo numérico para o cálculo das taxas. O módulo numérico do Vensim calcula as demandas para cada tipo de uso da terra e as disponibiliza para a rotina de expansão do desmatamento do modelo espacial.

\subsubsection{Construção de estrada BR-319 e estradas laterais}

A construção de estradas no modelo DINAMICA está dividida em duas instâncias, uma delas constituída por uma rotina interna de construção automática e outra por rotina de incorporação de mapas de estradas planejadas.

A rotina automática, ou "construtor de estradas", é formada por três módulos automáticos, o principal constrói estradas com base na localização probabilística de destinos. A distância destes destinos é regulada pelo estado de atividade. Um "construtor de estradas" mais ativo significa destinos mais distantes (estradas de penetração), e menos ativo compreende destinos mais próximos (estradas de consolidação). O segundo módulo calcula o custo do trajeto até o destino, este custo é calculado com base na fricção (Soares-Filho et al., 2002), por exemplo, atravessar áreas com maior declividade, áreas inundadas e áreas protegidas produzem trajetos de maior custo. O terceiro módulo está relacionado com a regulação da atividade. Neste módulo é comparado o mapa de desmatamento, correspondente a uma dada iteração com o mapa da rede de

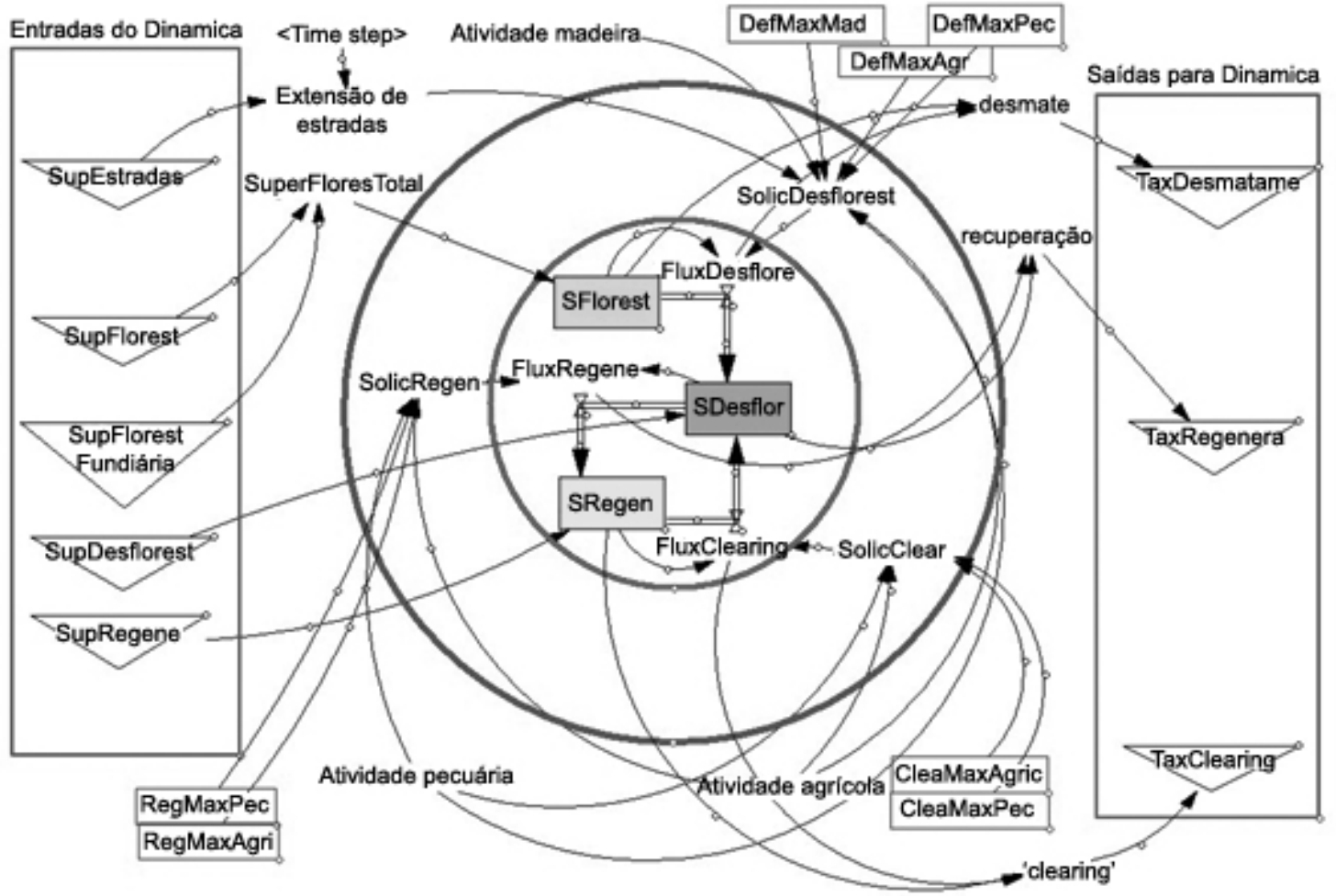

Figura 10 - Esquematização do modelo numérico elaborado em Vensim. O módulo principal de cálculo e os módulos de transferência das variáveis localizados no centro da figura (anéis concêntricos); à esquerda, a entrada de variáveis iniciais do Dinamica no modelo não-espacial e, à direita, a saída das taxas para o modelo espacial. 
estradas correspondente. Desta maneira, uma proporção alta de estradas que tenha produzido desmatamento, resulta em um aumento da atividade do "construtor de estradas". Este é um mecanismo de auto-regulação que aproxima o comportamento do autômato ao esperado na realidade.

\subsubsection{Incorporação de estradas planejadas}

As estradas planejadas são incorporadas ao modelo em etapas predefinidas, relacionadas com datas estimadas de construção extraídas do plano diretor do Estado. Entre estas estradas foram incluídas as do segmento central da BR-319 (trecho Realidade-Igapó Açu) no ano 2011, a estrada vicinal BR-319-Manicoré (AM-464), atualmente abandonada, no ano 2014, a vicinal BR-319-Borba (AM-356) no ano 2017, BR-319Tapauá (AM-366) projetada para conectar via terrestre a região de Coari, Tapauá-Coari (AM-365) ano 2021 e BR-319-Nova Aripuanã (AM-360) no ano 2024.

\subsubsection{Construtor de estradas com ciclos de atividade}

O construtor de estradas aumenta sua atividade, quando a maioria das estradas tem produzido desmatamento nas suas proximidades. Deste modo, a atividade de construção varia em relação com a saturação das estradas com desmatamento. $\mathrm{O}$ ciclo de atividade baixo está relacionado com destinos na ordem de $2 \mathrm{~km}$, o que em geral significa o adensamento da rede de estradas ou construção de estradas de consolidação. O ciclo médio utiliza destinos ao dobro do ciclo menos ativo, e o ciclo alto localiza destinos a $6 \mathrm{~km}$ e em geral os traçados configuram estradas de penetração. Este tipo de estrada é orientado pelos traçados preferenciais localizados em mapas de fricção nos quais se baseia o cálculo dos custos dos traçados.

\subsubsection{Construtor de estradas com traçados preferenciais}

A trajetória das estradas não está completamente relacionada com o cálculo simples de custos e atratividade, mas também é definida pelo padrão espacial de construção característica na região da simulação. Estes padrões podem ser observados na construção de estradas vicinais (ramais ou travessões) a cada $15 \mathrm{~km}$ nas estradas principais. Assim como, estradas de penetração em sentido radial ao adensamento da ocupação e malha viária de consolidação condicionada pela disposição fundiária de lotes, entre outras variáveis que são utilizadas para a formação dos mapas de atratividade e fricção correspondentes a cada ciclo da simulação (iteração).

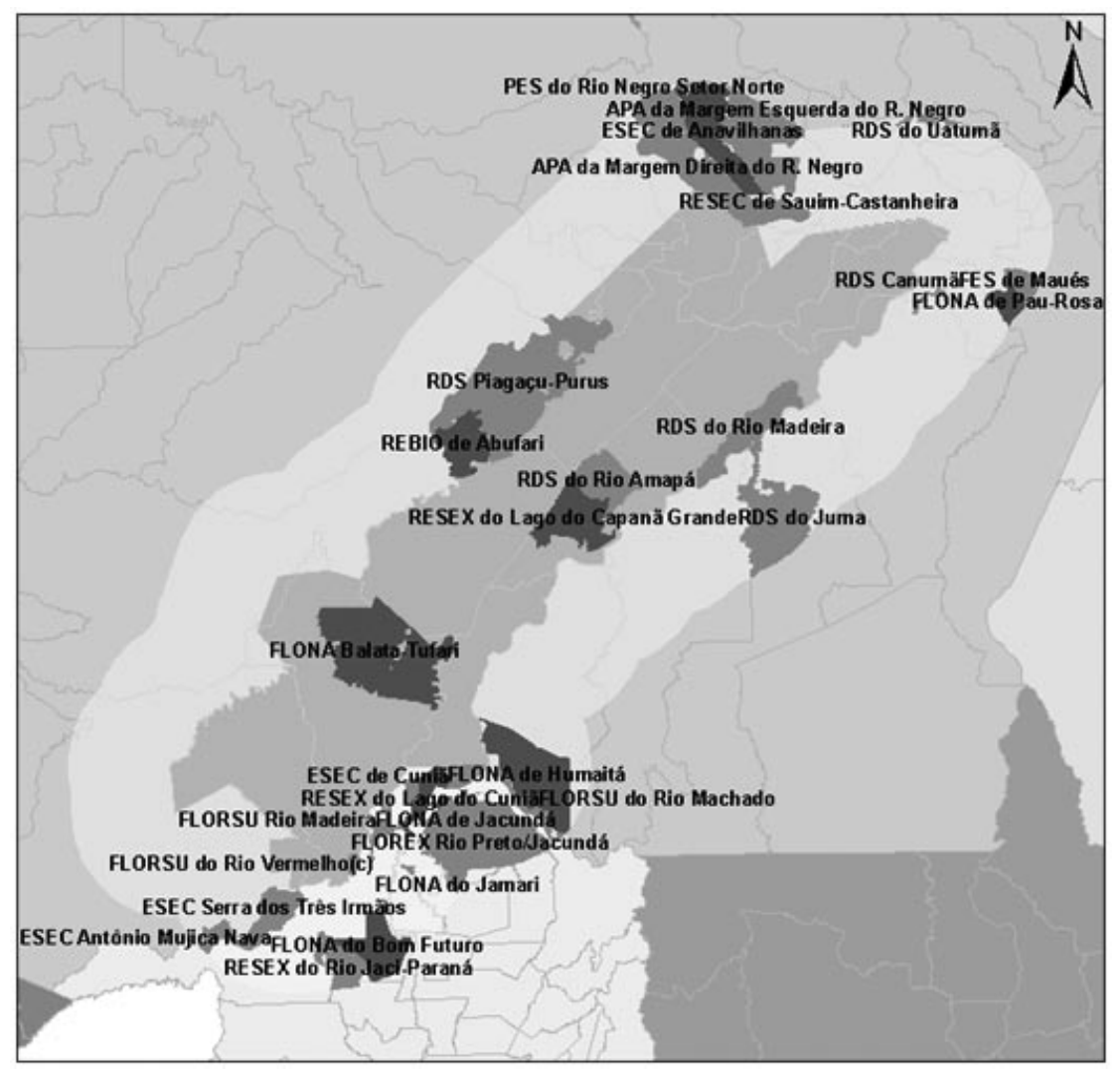

Figura 11 - Mapa com unidades de conservação estaduais e federais 


\subsubsection{Unidades de conservação existentes e propostas}

O modelo desenvolvido considera a inclusão de unidades de conservação existentes e, também, aquelas propostas para a ALAP da BR-319.

\subsubsection{Modelo Vensim}

O modelo desenvolvido no Vensim representa apenas um esqueleto para receber futuros componentes para representar os efeitos de fatores macroeconômicos e de políticas públicas que afetam os preços e, portanto, o lucro do desmatamento. As flutuações simuladas nas taxas de desmatamento seriam maiores com a incorporação destes efeitos não-espaciais importantes. As flutuações, nas taxas internas de desmatamento nas simulações atuais, se devem a ciclos na estimulação de desmatamento pela extensão da rede de estradas, aumentando em pulsos a área "disponível" ao desmatamento, o que representa um padrão concordante com o nosso entendimento do padrão temporal do desmatamento real (e.g., Fearnside, 1989).

\subsection{Cenários para A Região}

\subsubsection{Cenário de referência}

Na primeira fase deste estudo o modelo é executado para o cenário de referência com as seguintes suposições:

I. As unidades de conservação e as terras indígenas implementadas até 2007 estão incluídas na análise (veja mapa das unidades de conservação, Figura 11, e as terras indígenas, Figura 12);

II. A implementação das unidades de conservação existentes é eficaz e não têm desmatamento no seu interior;

III. Não há desmatamento dentro das terras indígenas.

\subsubsection{Cenário Conservação}

Suposições do cenário chamado Conservação (Figura 13) foram:

I. As unidades de conservação e terras indígenas implementadas até 2007 estão incluídas na análise;

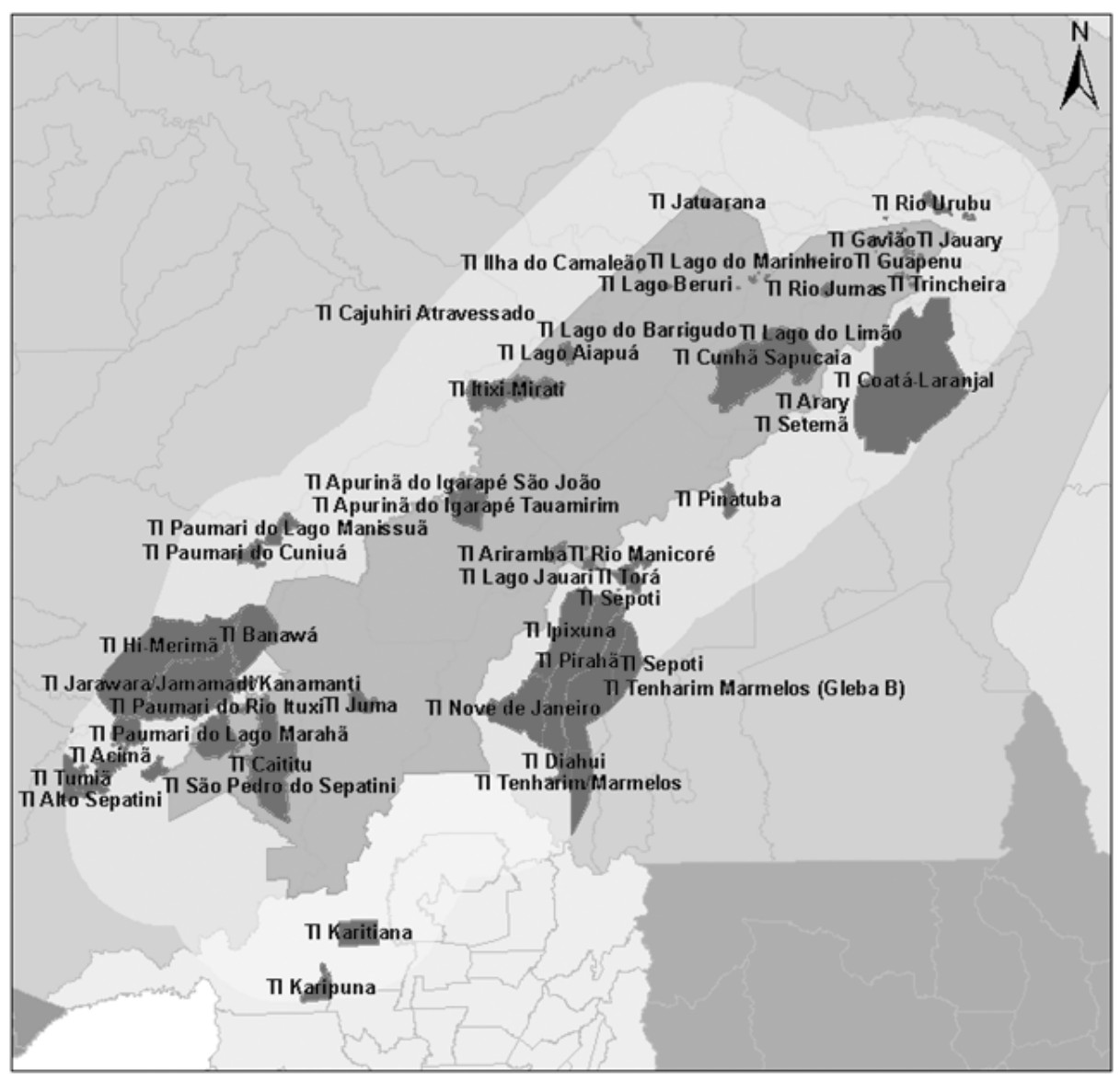

Figura 12 - Mapa de terras indígenas na área da ALAP com zona de "buffer" de 100 km 
II. As unidades de conservação propostas para a área de ALAP-BR-319 estão incluídas na análise;

III. A implementação das unidades de conservação existentes e propostas é eficaz e não têm desmatamento dentro das áreas;

IV. Não tem desmatamento dentro das terras indígenas;

\subsection{Dados espaciais de entrada}

Dados espaciais de entrada para o modelo são:

I. Mapas de cobertura da terra de tempo inicial $\left(t_{1}\right)$ (derivados dos dados de desmatamento do PRODES para o ano 2000, Brasil, INPE, 2007) e o tempo seguinte $\left(t_{1}+x\right)($ derivados dos dados do PRODES referentes a 2004, Brasil, INPE, 2007) para cálculo da taxa de transição e para o cálculo dos pesos de evidência, veja Figura $14 \& 15$.

II. Mapas de variáveis estáticas (discretas e contínuas):

a. Tipo de solo (RADAMBRASIL)

b. Tipo de vegetação (IBGE/SIPAM)

c. Altitude (SRTM)

d. Declividade (derivado do SRTM)

e. Distância aos rios (ANA)

f. Distância estradas primárias (CSR-UFMG)

g. Distância estradas secundárias (CSR-UFMG)

h. Atratividade a centros urbanos (derivado de IBGE)

O mapa de distâncias às estradas é apresentado na Figura 16.

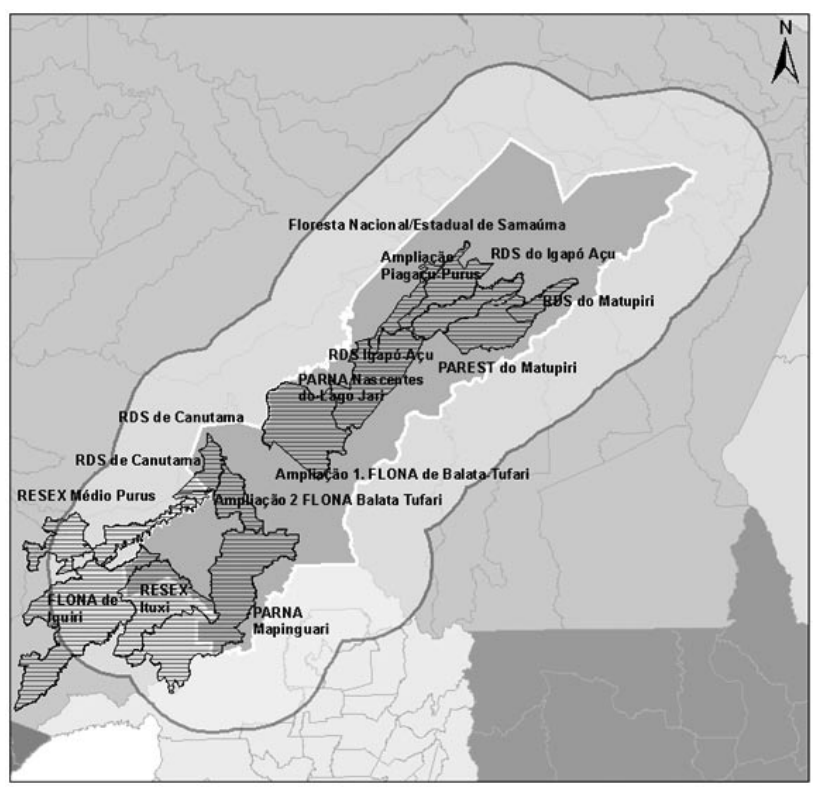

Figura 13 -Mapa das unidades de conservação propostas para a regiao da ALAP

\section{Mapa de friç̧ão}

O mapa de fricção foi elaborado a partir de dados de declividade e áreas de proteção ambiental (UCs), existentes nos cenários. A fricção é uma variável que influencia a atividade do módulo de construtor de estradas.

\section{Mapa de atratividade}

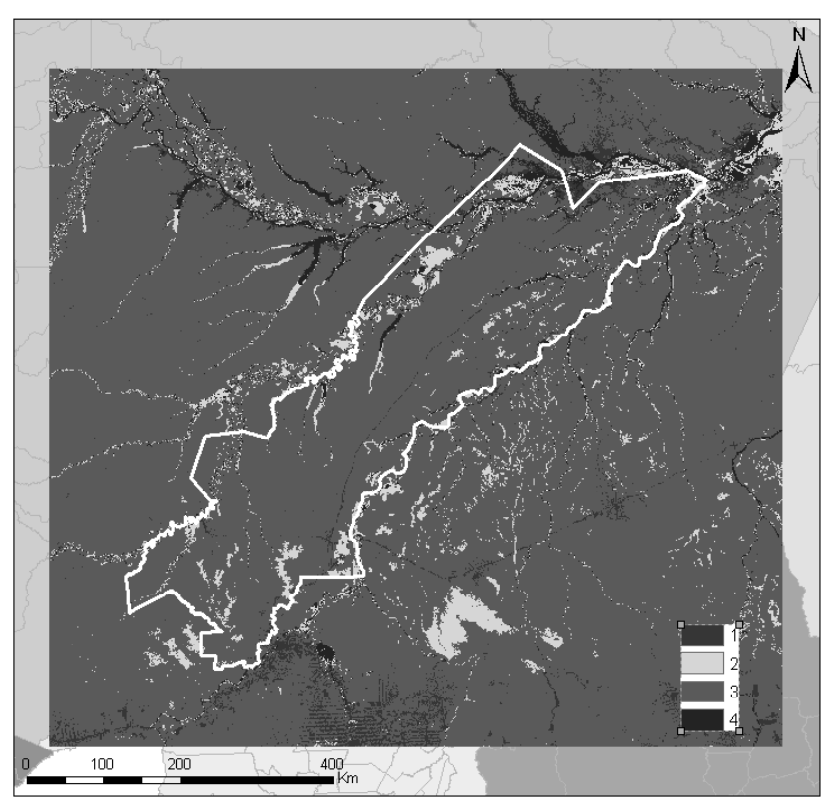

Figura 14 -Mapa cobertura da terra no ano 2000. Legenda do mapa: 1-Desmatamento; 2- Não-floresta; 3- Floresta; 4- Água.

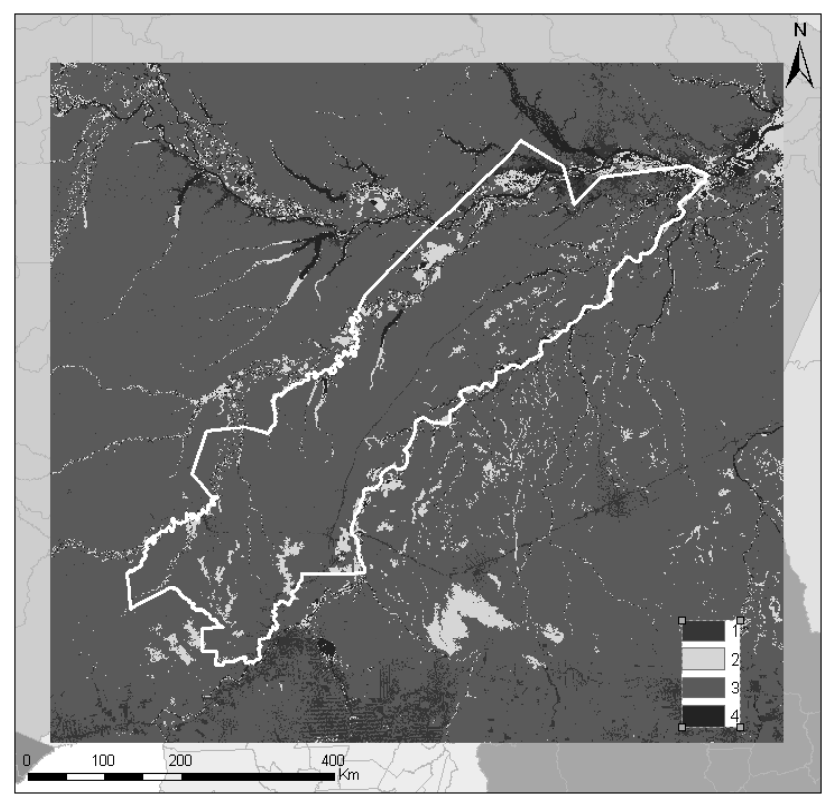

Figura 15 -Mapa cobertura da terra no ano 2004. Legenda do mapa: 1-Desmatamento; 2- Não-floresta; 3- Floresta; 4- Água. 
O mapa de atratividade (Figura 17) é calculado a partir da propriedade de áreas que funcionam como pólos de atração de atividade humana, tais como mapas de aptidão agrícola, áreas inundáveis e reservas de proteção. Estas duas últimas possuem baixa atratividade. Esse mapa também orienta a atividade do módulo de construtor de estradas.

\subsection{Estabelecimento de relações funcionais}

\subsubsection{Relação entre estradas e taxa de desmatamento}

A construção de estradas incorpora a superfície de floresta, atualizada a cada iteração, ao sistema da simulação. Esta incorporação está definida por uma faixa de $10 \mathrm{~km}$ (buffer) a ambos os lados das estradas. A superfície assim definida é denominada de floresta acessível. Deste modo, a superfície de floresta acessível pode aumentar no máximo de $20 \mathrm{~km}^{2}$, em cada quilômetro de estrada construída nos casos de estradas de penetração. Nos casos de estradas vicinais ou ramais, o aumento da superfície disponível pode ser até nula.

A incorporação de superfície de floresta disponível é minimizada, quando existem áreas de proteção integral ou terras indígenas vizinhas ao traçado, estas áreas não se incorporam à floresta disponível. A construção de estradas também é inibida pela presença de áreas de proteção integral. Nestes casos o incremento da superfície de floresta disponível pode ser zero, quando a construção de estradas acontece nas proximidades ou dentro das áreas de proteção, assim a superfície desmatada também

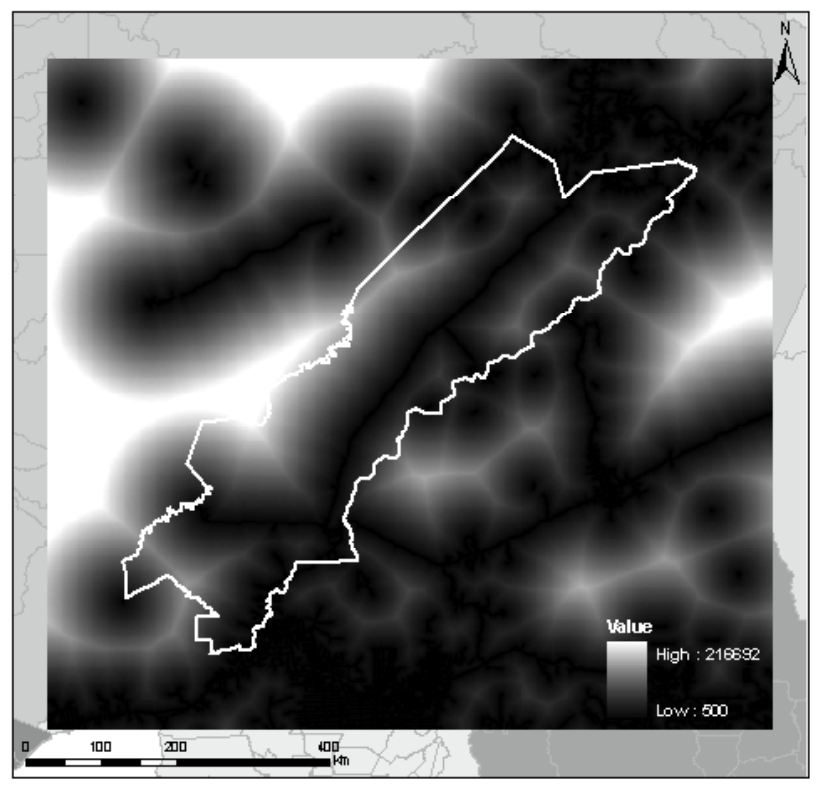

Figura 16 -Mapa de distância às estradas não aumentará, embora as estradas possam ser de penetração.

Este conceito de acessibilidade implica que a atividade de construção de estradas aumenta positivamente o desmatamento, através da aplicação das taxas internas de desmatamento segundo a Equação 1, na qual a superfície desmatada corresponde àquela desmatada no ciclo correspondente:

Sup. desmatada $=\mathrm{T} x$ interna $\times$ Sup. floresta.acessível

onde Sup. desmatada representa a superfície total desmatada em um dado ciclo; Tx.interna refere-se às taxas de desmatamento calculadas a partir da disponibilidade de áreas acessíveis ao desmatamento; Sup.floresta.acessível representa a superfície total de floresta capaz de ser utilizada para o desmatamento. Nesta equação observa-se que, embora a taxa interna de desmatamento possa não variar, a superfície desmatada em cada ciclo varia com as variações da superfície de floresta acessível.

\subsubsection{Superfície fundiária e floresta disponível}

A atividade de desmatamento é formada por uma atividade basal constante associada a uma superfície fundiária. Esta superfície é constituída por todas as células localizadas a menos de $2 \mathrm{~km}$ do traçado das estradas. Isto está relacionado com uma atividade de desmatamento de pequenas propriedades agropecuárias, que em geral muda pouco com as variações econômicas. Esta superfície estreita constitui uma faixa muito atrativa para o desmatamento, e se ajusta conforme a variações da densidade da rede de estradas.

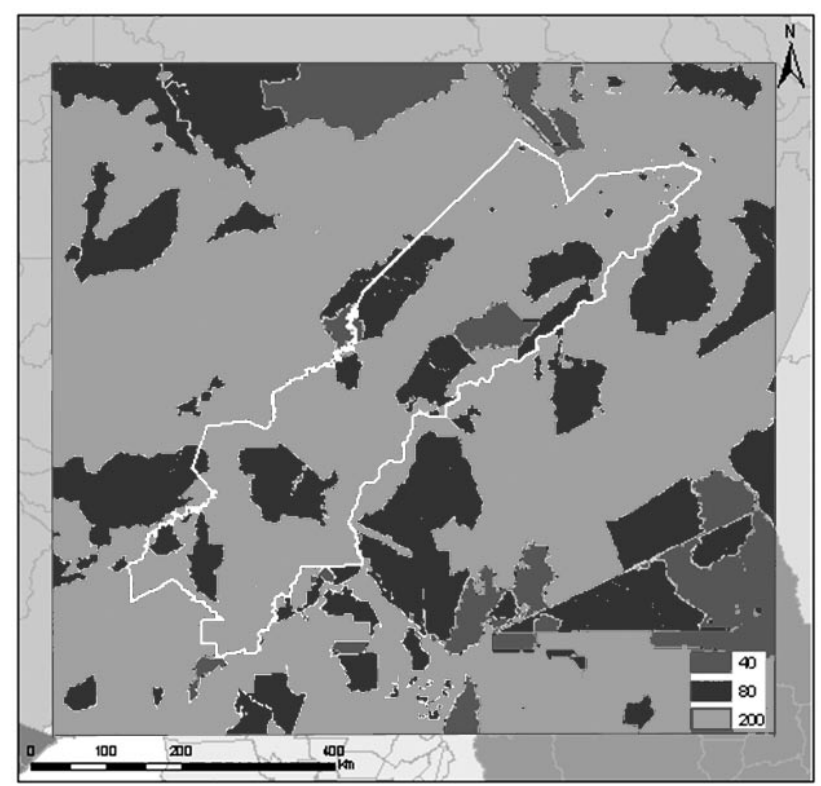

Figura 17 -Mapa de atratividade. A legenda do mapa refere-se aos valores de pesos de atratividade. 


\subsubsection{Variáveis do DINAMICA que alimentam o Vensim}

As variáveis geradas no DINAMICA são exclusivamente de superfície, as principais são: superfície de floresta, área desmatada, área de capoeiras e área fundiária. Estas variáveis são incorporadas ao modelo de simulação numérica do Vensim para produzir uma taxa de desmatamento, uma taxa de clearing (corte de capoeira) e uma taxa de recuperação.

\subsubsection{Modificações nos modelos existentes de DINAMICA}

As seguintes modificações foram realizadas nos modelos existentes desenvolvidos na Universidade Federal de Minas Gerais (Soares-Filho et al., 2003, 2004, 2006):

I. Acoplamento do modelo espacial DINAMICA com o modelo numérico do programa Vensim;

II. Construtor de estradas ativado por raio de alcance de estradas para desmatamento, alternando entre atividades de construção para extensão da rede e para penetração na floresta;

III. Construtor de estradas orientado por estradas planejadas para o futuro;

IV. Busca por destinos pelo construtor de estradas com preferência às áreas planas e de platô, evitando áreas alagadas;

V. Geração de um mapa de atratividade para o desmatamento baseado na densidade de estradas;

VI. Geração de uma superfície de floresta acessível com base no mapa de estradas, este valor de superfície é fornecido ao modelo Vensim;

VII. Geração da extensão de estradas sem desmatamento, fornecida ao modelo Vensim.

VIII geração de uma superfície de floresta disponível para atividade fundiária, definida pela distância menor de 2 $\mathrm{km}$ das estradas.

\subsubsection{Calibração do modelo}

O software DINAMICA-EGO fornece uma série de operadores especialmente desenvolvidos para calibração e validação (Rodrigues et al., 2007). No desenvolvimento do modelo de mudança do uso e cobertura da terra (LUCC) existem diferentes momentos de calibração do modelo. Uma das ferramentas de calibração do modelo é o calculo da taxa de transição das classes de cobertura. Neste caso particular da modelagem de desmatamento, a transição na região modelada é de floresta para área desflorestada. Dados de desmatamento obtidos do projeto PRODES (Brasil, INPE, 2007) do período 2000 até 2004 , são utilizados para o cálculo da taxa de transição e para analisar a tendência de desmatamento por ano para o período 2000-2006 em diferentes locais da região da Amazônia Central, entre Manaus e Porto Velho e ao longo da Transamazônica (BR-230) (ver Figura 18). A taxa anual foi derivada a partir da média anual calculada para o período 20002004. A taxa de transição no modelo adaptado neste estudo é calculada a partir de dados de desmatamento, apenas na primeira iteração, sendo atualizada a cada iteração pelo modelo numérico desenvolvido no Vensim.

\subsubsection{Validação do modelo}

O resultado global foi validado em sua aplicação para a área de Matupi (Figura 19). Aqui a quantidade e o padrão espacial do desmatamento simulado confirmam de forma aproximada o que é observado nas imagens de satélite (PRODES)(Brasil INPE, 2007). Porém, deve ser notado que o tipo de desmatamento representado aqui é produzido por pequenos agricultores, como aqueles ao norte da área da barragem de Samuel, em Rondônia, onde a relação foi estabelecida entre estradas e a expansão de desmatamento. Os efeitos de outros atores também precisam ser modelados (veja seção em melhorias futuras). Em geral, estes outros atores (grandes fazendeiros) produzirão desmatamento mais rápido.

\subsection{Resultados sobre desmatamento}

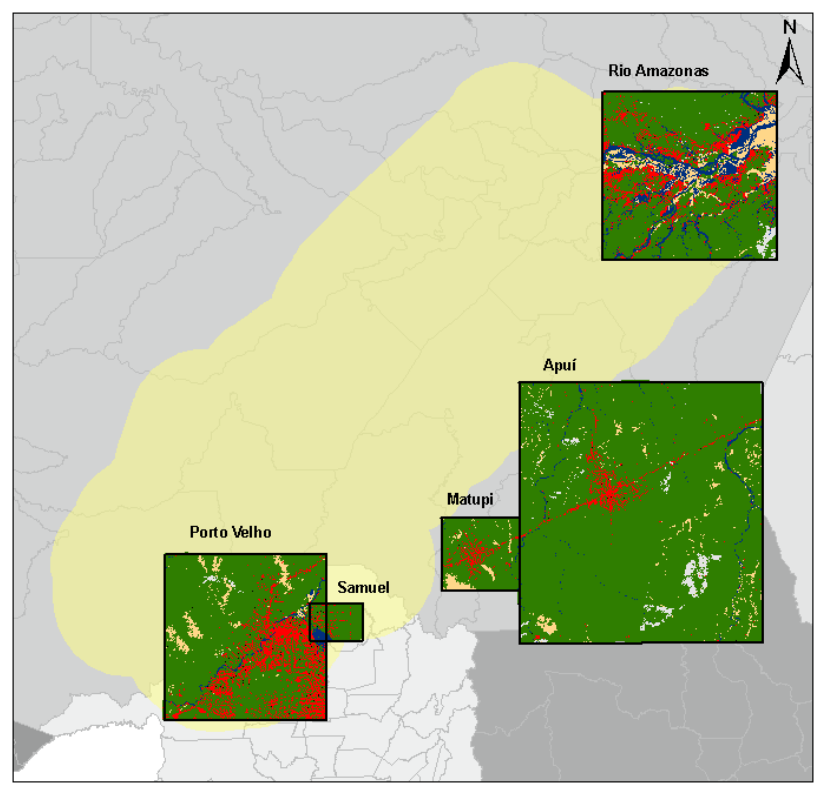

Figura 18 -Mapa das subáreas na região da ALAP, as quais foram utilizadas para análise dos padrões temporais de desmatamento. Nas sub-áreas as cores representam: verde - floresta; amarelo - não-floresta; vermelho - desmatamento; azul - água; branco - sem dados. 


\subsubsection{Cenário de referência}

Os resultados da simulação utilizando o cenário de referência são apresentados nas Figuras 20 e 21.

O percentual desmatado resultante da simulação que teria acontecido na cobertura florestal das áreas de reservas de proteção propostas pelo governo, caso que não fossem criadas, está indicado na Tabela 1 . As percentagens desmatadas até 2050, nas unidades de conservação indicada pelo modelo deste estudo, variam desde 0,4 até $77,6 \%$ no cenário de referência.

Características:

I. No cenário de referência a área de desmatamento projetada para 2050 chega até $33 \%$ da área da floresta original.

II. O aumento da taxa de desmatamento no intervalo entre os anos 2004 e 2015 está relacionado com a construção das estradas planejadas e a reconstrução e asfaltamento da BR-319.

\subsubsection{Cenário conservação}

Os resultados da simulação considerando o cenário de conservação são apresentados nas Figuras 22 e 23.

Características:

I. No cenário Conservação a área desflorestada projetada para 2050 chega até $25 \%$ da área da floresta original.

II. O aumento da taxa de desmatamento no intervalo entre os anos 2004 e 2015 está relacionado com a construção das estradas planejadas e a reconstrução e asfaltamento da BR-319.

\section{Modelo}

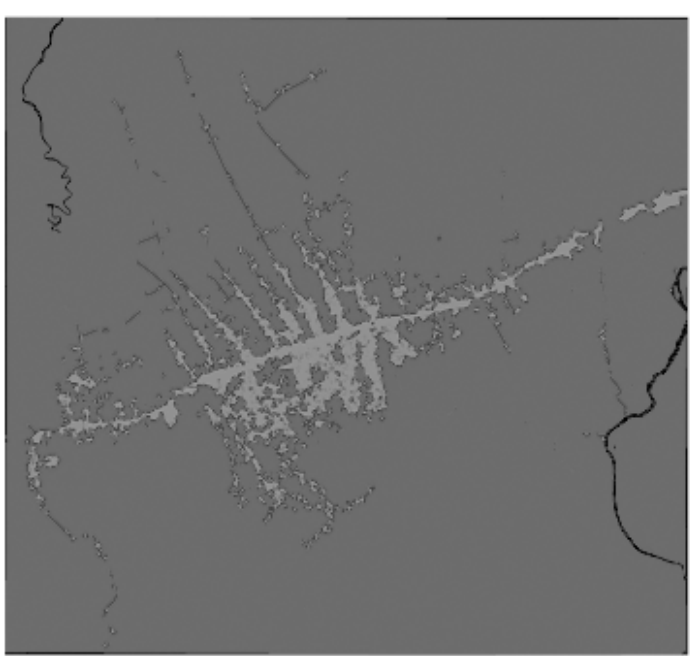

\section{BIOMASSA E EMISSÕES}

\subsection{Biomassa florestal na área de influência da BR- 319}

\subsubsection{Estimativa da biomassa florestal dos ecossistemas terrestres}

A biomassa total ${ }^{(1)}$ dos diferentes ecossistemas terrestres presentes ao longo da área de influência da BR-319, foi calculada a partir dos dados de volume de madeira comercial $\left(\mathrm{m}^{3} \mathrm{ha}^{-1}\right) \mathrm{de}$ 306 parcelas (1 ha cada), amostradas pelos inventários florestais do Projeto RADAMBRASIL realizados entre os estados de Rondônia (35 parcelas; 11,4\%) e Amazonas (272 parcelas; 88,6\%) (Brasil, Projeto RADAMBASIL, 1973-1984). Cada parcela amostrada pelo Projeto RADAMBRASIL nesta região da Amazônia, representa o resultado do volume total de madeira comercial com circunferência à altura do peito (CAP) maior ou igual a $100 \mathrm{~cm}$ (correspondente a $31,8 \mathrm{~cm}$ de DAP - diâmetro à altura do peito), exclusivamente para sistemas florestais.

Para transformar os dados de volume de madeira em biomassa por unidade de área $\left(\mathrm{t} \mathrm{ha}^{-1}\right)$, foram utilizados como método os fatores de expansão de volume (VEF $=1,25$ para florestas densas e 1,5 para não-densas) para adicionar os volumes correspondentes aos fustes das árvores menores (com DAP entre 10 e $31,7 \mathrm{~cm})$. A densidade de madeira média ponderada pelas espécies ocorrentes em cada parcela foi utilizada para converter o volume dos fustes em biomassa dos fustes. A biomassa das copas foi acrescentada utilizando um fator de expansão de biomassa

\section{Dados PRODES}

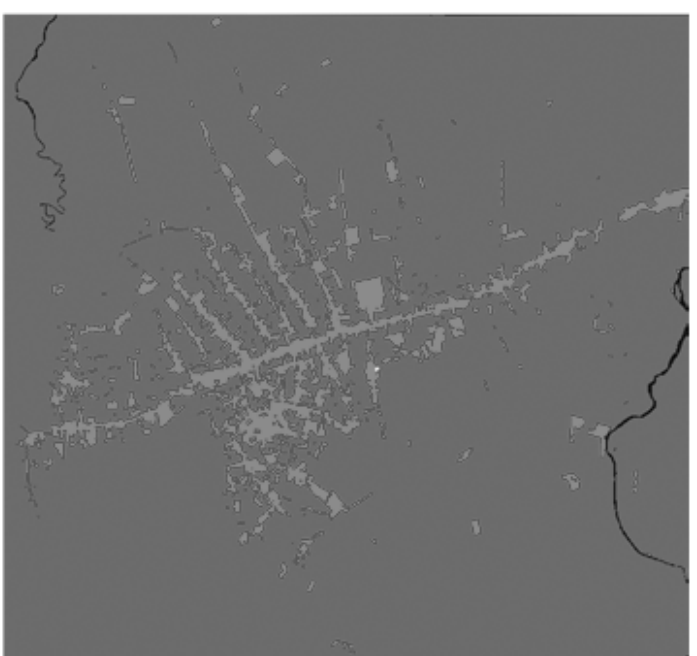

Figura 19 - Comparação entre o desmatamento modelado e observado em Matupí, provendo alguma validação os resultados globais do modelo.

\footnotetext{
${ }^{(1)}$ Neste trabalho, entenda-se biomassa total como o conjunto da massa vegetal (viva e morta) presente em cada um dos ecossistemas terrestres (acima + abaixo do solo).
} 
(BEF), conforme descrito originalmente por Brown \& Lugo (1992) e Brown (1997). Esta expansão de volume em biomassa foi posteriormente refinada, através de ajustes propostos por Fearnside (1992), que adicionam outros compartimentos da biomassa florestal que não estavam contemplados no modelo de Brown \& Lugo (1992). Os dados de densidade de madeira foram corrigidos para a variação radial, conforme resultados obtidos em floresta densa na Amazônia central (veja Nogueira et al., 2005). Os ecossistemas não florestais (vegetação aberta, com menor abundância de espécies e indivíduos) presentes na área de influência não foram contemplados pelos inventários de volume de madeira do Projeto RADAMBRASIL, e estão desprovidos de estimativas confiáveis.

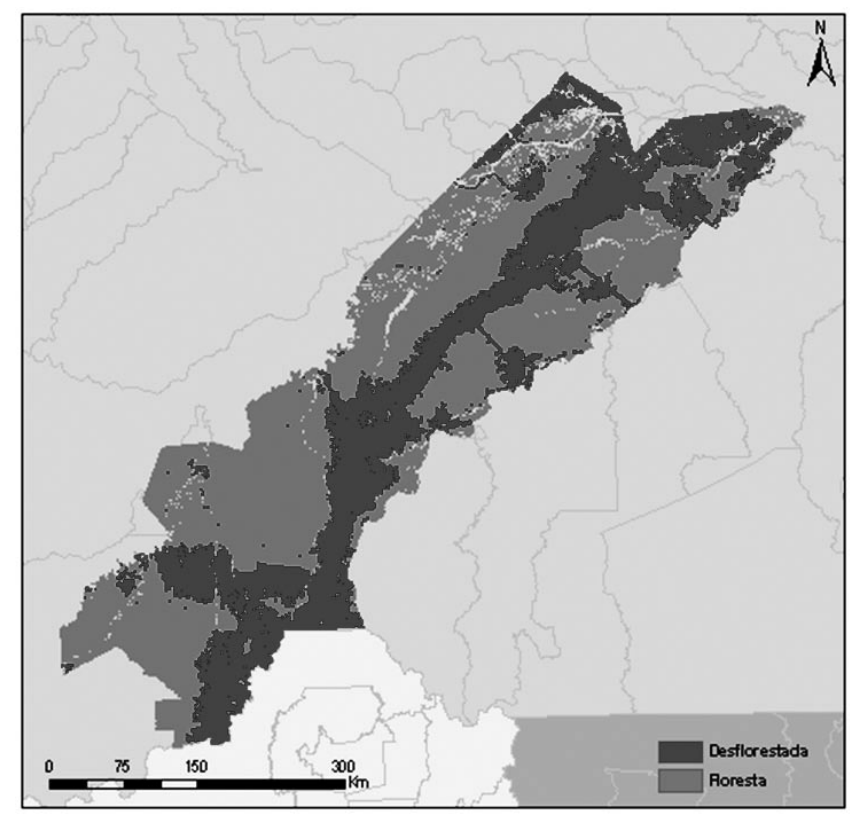

Figura 20 - Mapa desmatamento até 2050, cenário de referência

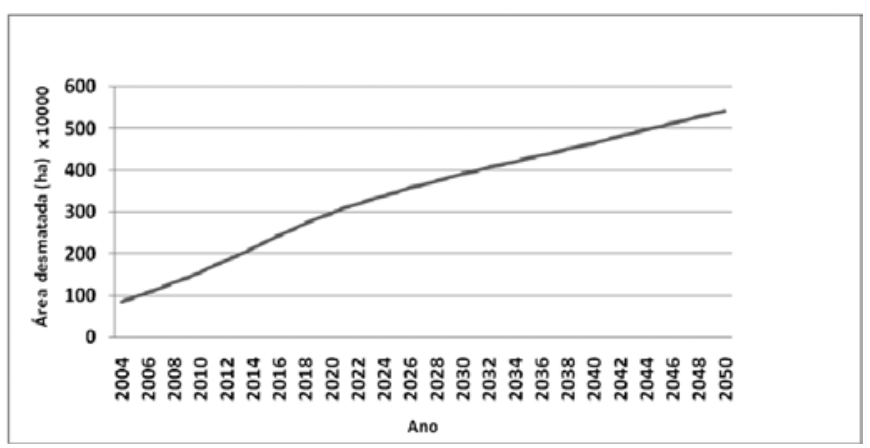

Figura 21 - Área desmatada acumulada, cenário de referência

\subsubsection{Base dos cálculos}

Para realizar os cálculos gerais, todas as 306 parcelas selecionadas para a área de abrangência da BR-319, foram dimensionadas em um banco de dados georreferenciado. Este banco foi formatado a partir de duas fontes básicas: (1) banco de dados georreferenciado do SIVAM/SIPAM (Brasil, SIVAM/ SIPAM, 2004), versão 6, para toda a Amazônia Legal Brasileira (escala 1:250.000), juntamente com um conjunto geral das informações fornecidas pelo IBGE ao SIVAM sobre a base de dados do Projeto RADAMBRASIL, e (2) livros de levantamento de recursos naturais(volumes) e mapas temáticos (solos, vegetação, etc.) do próprio RADAMBRASIL publicados pelo Ministério das Minas e Energia (MME), nas décadas de 1970 e 1980 (escala 1:1.000.000) (Brasil, Projeto RADAMBRASIL, 1973-1984). O resultado bruto dos inventários (volume da madeira com casca, número de espécies e de indivíduos) foi obtido das publicações do MME, enquanto que a base física (localização dos pontos amostrais) das espécies botânicas do inventário foi extraída do banco de dados do SIVAM. Embora nesta última fonte houvesse incertezas devido a vários erros de digitação nas informações de circunferência do tronco ou na altura comercial, foi possível utilizá-la para obter estimativas de densidade da madeira (crucial nos cálculos gerais) por cada unidade amostral de acordo com a as espécies presentes em cada parcela.

As definições fitofisionômicas (ecossistemas) adotadas na base de cálculo foram todas derivadas do manual técnico da vegetação brasileira (Brasil, IBGE, 1992), que é a referência para

Tabela 1 - Reservas propostas e desmatamento simulado*

\begin{tabular}{|c|c|c|c|}
\hline$\cdot$ & Nome da Unidade de Conservação & 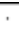 & Desmatamento (\%) \\
\hline$\cdot$ & RDS do Igapó Açu & $\cdot$ & 77,6 \\
\hline$\cdot$ & RDS Igapó-Açu & . & 74,8 \\
\hline$\cdot$ & PARNA Nascentes do Lago Jari & $\cdot$ & 64,1 \\
\hline$\cdot$ & Ampliação 2. FLONA Balata Tufari & 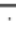 & 43,6 \\
\hline$\cdot$ & PARNA Mapinguari & . & 29,1 \\
\hline$\cdot$ & Floresta Nacional/Estadual de Samaúma & . & 15,2 \\
\hline$\cdot$ & RESEX Médio Purus & $\cdot$ & 10,8 \\
\hline . & Ampliação 1. FLONA de Balata-Tufari & . & 10,2 \\
\hline$\cdot$ & FLONA de Iquiri & 7 & 10,0 \\
\hline$\cdot$ & RDS de Canutama & 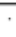 & 9,9 \\
\hline$\cdot$ & PAREST do Matupiri & . & 5,4 \\
\hline$\cdot$ & RESEX Ituxi & . & 2,6 \\
\hline$\cdot$ & Ampliação Piagaçu-Purus & . & 0,4 \\
\hline
\end{tabular}


a classificação das fitotipologias no País. Foram formados dois grandes grupos florestais para dar início ao processo de cálculo que transformaria volume em biomassa: "Floresta Densa" e "Floresta Não-densa". Ambos são o marco inicial para aplicação do VEF e do BEF. No primeiro grupo estão incluídas todas as formações primárias (aluvial, das terras baixas, submontana e montana) definidas dentro da classe de formação "floresta", subclasse de formação "ombrófila", subgrupo de formação "densa", conforme determina o sistema de classificação brasileiro. No caso das florestas não-densas, estão incluídas todas demais subclasses e subgrupos de formação florestal, como as florestas ombrófilas abertas, as campinaranas, as florestas estacionais deciduais e semideciduais, e todos os sistemas florestais de contato (p. ex. floresta ombrófila em contato com floresta estacional ou savana em contato com floresta ombrófila).

\subsubsection{Estimativas gerais}

Das 306 parcelas amostradas, $253(82,7 \%)$ estavam no grupo de Floresta Densa e 54 (17,6\%) no de Floresta Não-densa. Os ecossistemas com o maior número de parcelas amostrais foram os de Floresta Ombrófila Densa das Terras Baixas (Db; 156 parcelas) e Aluvial (Da; 62): quase todos dentro do estado do Amazonas e, o de menor amostragem foi a Floresta Ombrófila Aberta Aluvial (Aa; 9). Este último com apenas uma parcela no estado de Rondônia.

A biomassa média total (não ponderada pela área de cada sistema) calculada neste trabalho foi de $414 \mathrm{t} \mathrm{ha}^{-1}$ (277604 t.ha $^{-1}$ ) (Tabela 3). Os demais sistemas terrestres presentes

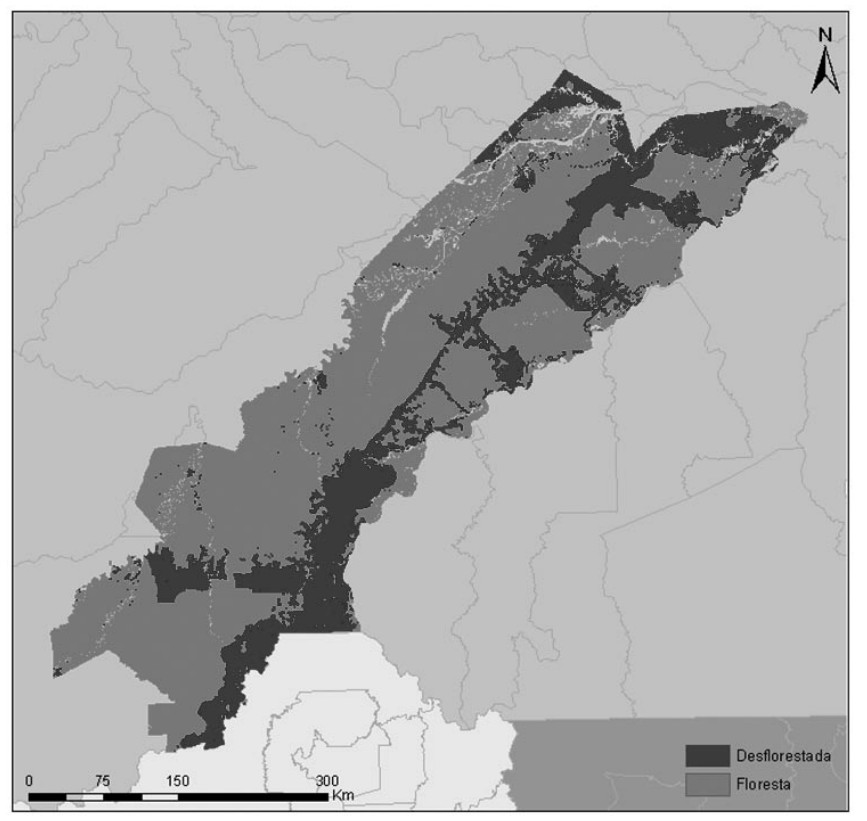

Figura 22 - Área desmatada acumulada, cenário de referência na amostragem do Projeto RADAMBRASIL, continham um maior número de parcelas inventariadas e conseguiram diluir sua variabilidade na média final, não apresentando distorções. Todos estão dentro da faixa de resultados encontrados para a maioria dos trabalhos realizados na Amazônia (300-600 $\mathrm{t} \mathrm{ha}^{-1}$ ) utilizando os métodos de medidas direta e indireta disponibilizados na literatura corrente (Klinge \& Rodrigues, 1974; Fearnside et al., 1993; Fearnside, 1994; 1997; 2000a,b; Higuchi et al., 1994; Alves et al., 1997; Laurance et al., 1999; Nascimento et al., 2007).

Para comparação, os valores aqui calculados possuem uma diferença de $-75 \%$ em relação à aplicação direta da fórmula de expansão de volume em biomassa apresentada por Brown \& Lugo (1992), e de $+4,5 \%$ em relação ao refinamento apresentado posteriormente por Fearnside (1992) (ver Tabela 3). Os valores aqui relatados já possuem os mais recentes ajustes para densidade da madeira, por ecossistema e Estado (média geral de 0,651 g.cm ${ }^{-3}$ ), além de outros refinamentos como a eliminação de ajustes anteriores para "árvores ocas" e "casca", atualmente contemplados em outros níveis do cálculo.

Estes valores para biomassa incorporam uma série de melhorias em comparação com estimativas anteriores por ter resolvido problemas com relação à contabilidade de árvores ocas e irregulares e de fator de forma (Fearnside \& Laurance, 2004; Nogueira et al., 2006), e de diferenças regulares e significativas a cerca da densidade de madeira no arco de desmatamento em comparação com a Amazônia Central, mesmo para árvores de uma mesma espécie (Nogueira et al., 2007).

Os cálculos acima apresentados usam a biomassa da floresta original, sem ajuste pelos efeitos da exploração madeireira ou outras formas de degradação da floresta em pé. Desta maneira, as emissões associadas aos processos de degradação para as áreas desmatadas estão implicitamente incluídas, mas não para a degradação na floresta remanescente que não é desmatada logo (por exemplo, dentro de um prazo de

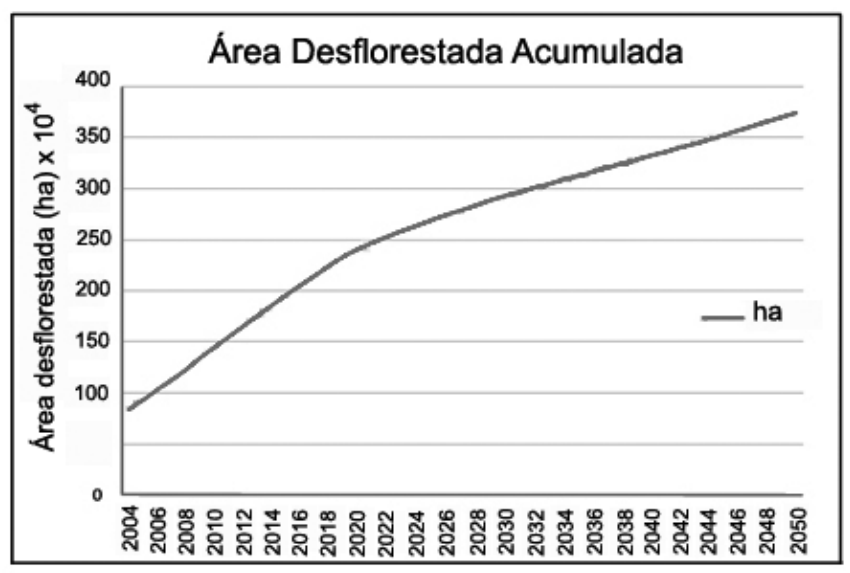

Figura 23 - Área desmatada acumulada, cenário "Conservação" 
três anos após a exploração madeireira). Se no futuro vierem a ser realizados cálculos explícitos de exploração madeireira e de outras emissões por degradação, a biomassa usada para calcular a emissão do desmatamento teria que ser ajustada adequadamente (veja discussão em Fearnside, 1997).

\subsubsection{Mapa e Características de Distribuição de Biomassa}

O mapa com as características de distribuição da biomassa naALAPdaBR-319éapresentadonaFigura24.Abiomassaémenor na parte sul da ALAP e aumenta ao longo do trajeto para Manaus.

\subsection{Estimativas de Emissões de Carbono}

A emissão total foi calculada a partir da perda do estoque de carbono de biomassa somando o efeito dos gases- traço. Apenas metano $\left(\mathrm{CH}_{4}\right)$ e óxido nitroso $\left(\mathrm{N}_{2} \mathrm{O}\right)$ foram considerados, porque os efeitos de outros gases-traço, tais como monóxido de carbono $(\mathrm{CO})$, óxidos de nitrogênio $\left(\mathrm{NO}_{\mathrm{x}}\right)$ e hidrocarbonetos não-metanos (NMHC) não são considerados atualmente pelo Painel Intergovernamental sobre Mudanças Climáticas (IPCC). A equivalência dos gases foi baseada nos potenciais de aquecimento global (GWPs) do Segundo Relatório de Avaliação do IPCC, e são os valores que foram adotados pelo Protocolo de Kyoto para uso durante o seu Primeiro Período de Compromisso (2008-2012). Usando essas equivalências, cada tonelada de $\mathrm{CH}_{4}$ tem o impacto sobre o aquecimento global de 21 toneladas de gás de $\mathrm{CO}_{2}$, enquanto que cada tonelada de $\mathrm{N}_{2} \mathrm{O}$ é equivalente a 310 toneladas de $\mathrm{CO}_{2}$, calculado ao longo de um horizonte de tempo de 100 anos (Schimel et al., 1996). Deve ser notado que o Quarto Relatório de Avaliação do IPCC (Forster et al., 2007, p. 212) altera estes valores. No caso de metano, o valor do GWP aumenta para 25 , uma elevação de $19 \%$ sobre

Tabela 2 - Distribuição das parcelas amostrais (inventários florestais) do Projeto RADAMBRASIL dentro das classes de floresta densa e não-densa, por ecossistema, utilizadas na área de influência da BR 319.

\begin{tabular}{|c|c|c|c|c|}
\hline Tipo Florestal & Legenda & $\begin{array}{c}\text { Floresta } \\
\text { Densa }\end{array}$ & $\begin{array}{c}\text { Floresta } \\
\text { Não-Densa }\end{array}$ & Total \\
\hline Floresta Ombrófila Densa (sem formação) & $\mathrm{D}$ ? & 8 & & 8 \\
\hline Floresta Ombrófila Densa Aluvial & Da & 58 & & 58 \\
\hline Floresta Ombrófila Densa das Terras Baixas & $\mathrm{Db}$ & 156 & & 156 \\
\hline Floresta Ombrófila Densa Submontana & Ds & 8 & & 8 \\
\hline Floresta Ombrófila Aberta (sem formação) & A? & & 1 & 1 \\
\hline Floresta Ombrófila Aberta Aluvial & $\mathrm{Aa}$ & & 9 & 9 \\
\hline Floresta Ombrófila Aberta das Terras Baixas & $\mathrm{Ab}$ & & 16 & 16 \\
\hline Floresta Ombrófila Aberta Submontana & As & & 6 & 6 \\
\hline Sem informação $(*)$ & si & 10 & & 10 \\
\hline Floresta Ombrófila Densa Aluvial & $\mathrm{Da}$ & 4 & & 4 \\
\hline Floresta Ombrófila Densa Submontana & Ds & 2 & & 2 \\
\hline Floresta Ombrófila Aberta Aluvial & Aa & & 1 & 1 \\
\hline Floresta Ombrófila Aberta das Terras Baixas & $\mathrm{Ab}$ & & 9 & 9 \\
\hline Floresta Ombrófila Aberta Submontana & As & & 11 & 11 \\
\hline Formações Pioneiras com influência fluvial & $\mathrm{Pa}$ & & 1 & 1 \\
\hline Sem informação $(*)$ & si & 7 & & 7 \\
\hline- & - & 253 & 54 & 307 \\
\hline
\end{tabular}

(*) 10 parcelas no Amazonas e 7 em Rondônia foram incluídas como floresta densa por comparação, embora o banco de dados do Brasil, SIVAM/ SIPAM (2004) não tenha fornecido esta informação (ecossistemas sem definição). si = sem informações. 
o impacto deste importante gás. No caso de óxido nitroso, o GWP foi reduzido para 298, uma diminuição de 4\%. Para estas emissões, o efeito do metano será maior, e o impacto atribuído ao desmatamento aumentará, quando essas novas informações forem incorporadas nas negociações internacionais. Usando os valores atuais do Protocolo de Kyoto, cada tonelada de carbono emitida tem um impacto adicional de gases-traço equivalente a 0,087 t C (toneladas de carbono), baseado nas emissões de 1990 calculadas por Fearnside (2000a,b).

A emissão líquida foi calculada a partir da emissão bruta, da qual foi subtraído o estoque médio de carbono na paisagem de equilíbrio que substitui a floresta. Isto contém $28,5 \mathrm{t} \mathrm{ha}^{-1} \mathrm{de}$ biomassa com um conteúdo de carbono de 0,45 , ou 12,8 t C $\mathrm{ha}^{-1}$ em biomassa (i.e., não considerando o carbono do solo), baseado em uma matriz de transições entre categorias de usos da terra (Fearnside, 1996).

Os cálculos acima das emissões causadas pelo desmatamento apenas incluem o carbono da biomassa viva e morta, excluído o carbono do solo. Uma estimativa de liberação de carbono do solo pela conversão da floresta amazônica na paisagem de substituição de equilíbrio é de $5,4 \mathrm{t} \mathrm{C} \mathrm{ha}^{-1}$, nos primeiros $20 \mathrm{~cm}$ de solo, 7,9 t C ha-1 no primeiro $1 \mathrm{~m}$ de solo,

Tabela 3 - Densidade básica da madeira $\left(\mathrm{g} . \mathrm{cm}^{-3}\right)$, volume $\left(\mathrm{m}^{3} \cdot \mathrm{ha}^{-1}\right)$ e biomassa (t.ha $\left.{ }^{-1}\right)$ dos ecossistemas florestais presentes na área de influência da BR 319.

\begin{tabular}{|c|c|c|c|c|c|}
\hline $\begin{array}{c}\text { Ecossistema } \\
\text { (legenda) }\end{array}$ & 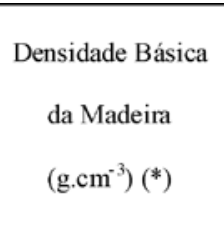 & $\begin{array}{c}\text { Volume } \\
\text { RADAMBRASIL } \\
\left(\mathrm{m}^{3} \cdot \mathrm{ha}^{-1}\right)\end{array}$ & $\begin{array}{c}\text { Biomassa } \\
\text { (Brown \& } \\
\text { Lugo, 1992) } \\
\text { t.ha }^{-1}{ }^{(* *)}\end{array}$ & $\begin{array}{c}\text { Biomassa } \\
\text { (Fearnside, } \\
1992) \\
\text { t.ha }^{-1}(* *)\end{array}$ & $\begin{array}{r}\text { Biomassa } \\
\text { (Este } \\
\text { Trabalho) }\end{array}$ \\
\hline $\mathrm{D}$ ? & 0.670 & 110 & 228 & 417 & 398 \\
\hline $\mathrm{Da}$ & 0.615 & 125 & 233 & 427 & 408 \\
\hline $\mathrm{Db}$ & 0.663 & 119 & 236 & 433 & 413 \\
\hline Ds & 0.668 & 121 & 237 & 434 & 415 \\
\hline A? & 0.668 & 42 & 159 & 290 & 277 \\
\hline $\mathrm{Aa}$ & 0.633 & 99 & 231 & 422 & 403 \\
\hline $\mathrm{Ab}$ & 0.673 & 106 & 248 & 454 & 433 \\
\hline As & 0.632 & 124 & 258 & 473 & 451 \\
\hline si & 0.663 & 126 & 242 & 443 & 423 \\
\hline $\mathrm{Da}$ & 0.636 & 145 & 257 & 471 & 450 \\
\hline Ds & 0.661 & 116 & 236 & 433 & 414 \\
\hline $\mathrm{Aa}$ & 0.631 & 210 & 345 & 632 & 604 \\
\hline $\mathrm{Ab}$ & 0.648 & 109 & 243 & 446 & 426 \\
\hline As & 0.631 & 100 & 232 & 424 & 405 \\
\hline $\mathrm{Pa}$ & 0.632 & 166 & 303 & 555 & 530 \\
\hline si & 0.646 & 104 & 211 & 386 & 369 \\
\hline- & 0.651 & 118 & 237 & 433 & 414 \\
\hline
\end{tabular}

(*) Valores de densidade básica da madeira são derivados do banco de dados geral para a Pan Amazônia (R. I. Barbosa, comunicação pessoal). (**) Os valores de biomassa total de Brown \& Lugo (1992) e Fearnside (1992) são apenas para comparação, não se resumindo no resultado final deste trabalho. $\mathrm{si}=$ sem informações. 
ou $8,5 \mathrm{tC} \mathrm{ha}^{-1}$ nos primeiros $8 \mathrm{~m}$ de solo (Fearnside \& Barbosa, 1998). O carbono do solo mais profundo leva mais tempo para ser liberado do que o carbono no solo superficial.

O cenário de referência resulta na liberação de $0,9 \mathrm{Gt} C$ até 2050, comparado com a liberação de 0,6 Gt C no cenário conservação. A maior parte da diferença entre os dois cenários se deve à taxa comparativamente menor de liberação de carbono no cenário conservação após o ano 2020 (Figura 25).

\section{MELHORIAS FUTURAS}

Embora o atual esforço de modelagem tenha produzido o que acreditamos ser um progresso para representar o processo de desmatamento, isto, de certo modo, reflete os papéis da construção da estrada e da melhoria e criação de áreas protegidas. Este tipo de cálculo "dirigido por infra-estrutura", ou mais geralmente, "dirigido por oportunidade", é essencial se as implicações de decisões de política são avaliadas. Não obstante, os modelos "dirigidos por demanda", também capturam aspectos importantes do processo de desmatamento, especialmente para fronteiras consolidadas. O desenvolvimento de modelos híbridos que combinam as duas abordagens, e o desenvolvimento de modelos baseados em agentes (atores), também conhecidos como "arranjos institucionais", representam o próximo passo.

Além dos efeitos macro-econômicos que determinam a demanda para os produtos de desmatamento, os papéis de vários grupos importantes de atores precisam ser modelados explicitamente. Estes incluem "grileiros" (os grandes apropriadores ilegais de terra), grandes investidores (i.e.,

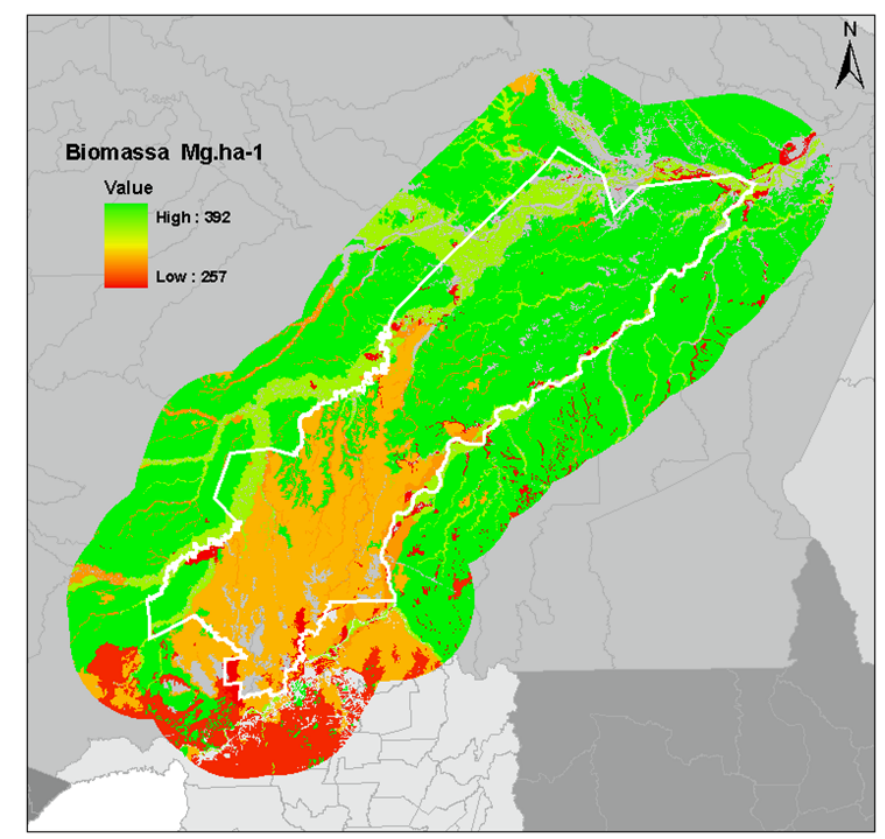

Figura 24 - Distribuição de biomassa (abaixo e acima do solo) na região da ALAP BR-319 agroindústria de soja e grandes pecuaristas) e fontes ilegais de dinheiro, em combinação ou não com a agropecuária (i.e., lavagem de dinheiro com renda de tráfico de drogas, corrupção, sonegação tributária e outras fontes ilegais). Além disso, é preciso modelar explicitamente o efeito da exploração madeireira, que influencia o desmatamento tanto por construir estradas endógenas, quanto por fornecer dinheiro aos proprietários de terras para investir na derrubada. $\mathrm{O}$ efeito mais amplo da rodovia sobre a migração também precisa ser modelado, pois este efeito não só estimula a expansão do desmatamento ao longo da rota da rodovia, como representado aqui, mas também seu papel como um canal para transportar população até o final da estrada em Manaus. Finalmente, os efeitos potenciais da necessidade de governança precisam ser quantificados e modelados, e isto deve ser feito baseado em dados de observações ao invés de suposições simples que postulam mudanças dramáticas de comportamento sem precedentes. Estas melhorias representam, principalmente, acréscimos ao modelo não espacial (em Vensim).

Necessidades futuras também incluem melhorias adicionais nas estimativas de biomassa de floresta e estoques de carbono, e das emissões que são o resultado do desmatamento e de perturbações na floresta, como a exploração madeireira, incêndios florestais e efeitos de borda. Também devem ser feitas análises com base em estoques de carbono, ao invés de restringir a consideração às mudanças nos fluxos de carbono por desmatamento reduzido. De uma forma mais geral, avaliações futuras têm que incluir a quantificação de uma gama mais larga de serviços ambientais, inclusive a ciclagem de água e a manutenção de biodiversidade.

\section{AGRADECIMENTOS}

A preparação deste trabalho foi financiada pela Iniciativa Amazonas (IA), Secretaria de Estado do Meio Ambiente e

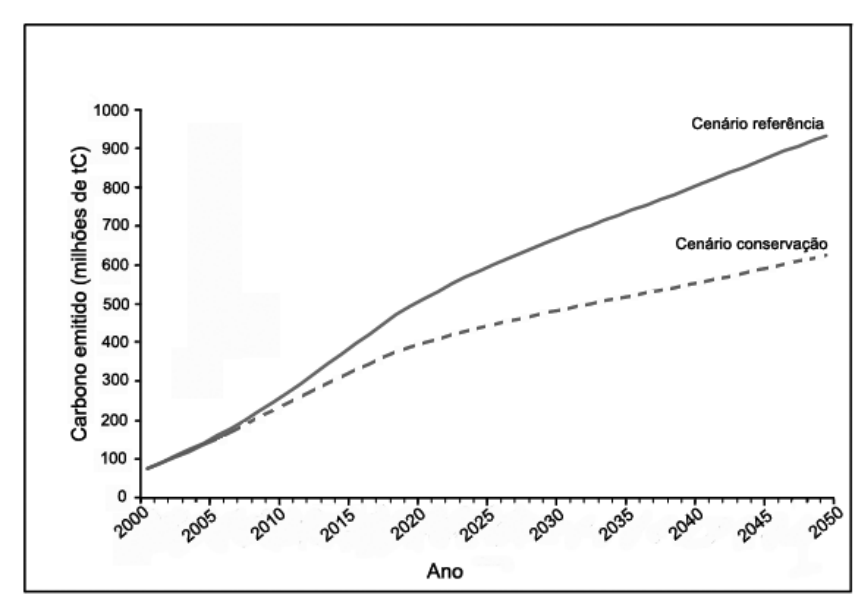

Figura 25 - Emissão de gases de efeito estufa nos cenários de referência e conservação 
Desenvolvimento Sustentável (SDS), Manaus, Amazonas, Brasil. Apoio financeiro ao estudo tem sido fornecido pelo Conselho Nacional do Desenvolvimento Científico e Tecnológico (CNPq) (306031/2004-3; 474548/2006-6; 557152/2005-4; 420199/2005-5), Rede GEOMA, FAPEAM e o Instituto Nacional de Pesquisas da Amazônia (PRJ05.57 \& PRJ02.12). Bruce Nelson e um revisor anônimo fizeram comentários úteis ao manuscrito.

\section{REFERÊNCIAS BIBLIOGRÁFICAS}

A CRÍTICA. "Estado e DNER recuperam 42 rodovias" A Crítica [Manaus], 10 de agosto de 1997, p. E-4, 1997.

AGUIAR, A. P. D. Modeling Land Use Change in the Brazilian Amazon: Exploring Intra-Regional Heterogeneity. Tese de doutorado em sensoriamento remoto, Instituto Nacional de Pesquisas Espaciais (INPE), São José dos Campos, São Paulo, Brasil. 153 p., 2006.

AGUIAR, A. P. D.; CÂMARA, G.; ESCADA, M. I. S. Spatial statistical analysis of land-use determinants in the Brazilian Amazonia: Exploring intra-regional heterogeneity. Ecological Modelling, v.209, p.169-188, 2007.

ALENCAR,A.; NEPSTAD, D.C.; McGRATH, D.; MOUTINHO, P.; PACHECO, P.; DIAZ, M. DEL C. V.; SOARES-FILHO, B. Desmatamento na Amazônia: Indo além da Emergência Crônica. Instituto de Pesquisa Ambiental da Amazônia (IPAM), Belém, Pará, Brasil. 87 p., 2004.

ALENCAR, A.; MICOL, L.; REID, J.; AMEND, M.; OLIVEIRA, M.; ZEIDEMANN, V.; DE SOUSA, W. C. A pavimentação da BR-163 e os desafios à sustentabilidade: uma análise econômica, social e ambiental. Instituto Centro de Vida (ICV), Cuiabá, Mato Grosso, Brasil. 25 p. Disponível em $<$ http://www.estacaovida.org.br/pdf/pavimentacaobr163. pdf $>, 2005$.

ALVES, D. S.; SOARES, J. V.; AMARAL, S.; MELLO, E. K.; ALMEIDA, S. A. S.; SILVA, O. F.; SILVEIRA, A. M. Biomass of secondary vegetation in Rondônia, Western Brazilian Amazon. Global Change Biology, v.3, p.451-461, 1997.

ANDERSEN L E; GRANGER, C. W. J.; REIS, E. J.; WEINHOLD, D.; WUNDER, S. The Dynamics of Deforestation and Economic Development in the Brazilian Amazon. Cambridge University Press. Cambridge, Reino Unido, 2002.

BARBOSA, R. I.; PINTO, F. S.; SOUZA, C. C. Desmatamento em Roraima: Dados Históricos e Distribuição Espaço Temporal. Instituto Nacional de Pesquisas da Amazônia (INPA), Boa Vista, Roraima, Brasil. Relatório Técnico Elaborado para Subsidiar as Discussões sobre Desmatamento no Estado de Roraima. Disponível em <http://agroeco.inpa.
gov.br/reinaldo/Usuarios_Visitantes_RIB.htm>, 2008.

BRASIL. Lei $n^{\circ} 4.771$, de 15 de setembro de 1965 que Institui o

Novo Código floresta. Disponível em $<$ http:/www.planalto. gov.br/ccivil_03/Leis/Referencia_Legislativa/L4771ref_leg. htm>, 1965.

BRASIL, IBGE. Manual Técnico da Vegetação Brasileira (Manuais Técnicos em Geociências no 1). Fundação Instituto Brasileiro de Geografia e Estatística (IBGE), Rio de Janeiro, Brasil. 92 p., 1992.

BRASIL, INPE. Projeto PRODES: Monitoramento da Floresta Amazônica Brasileira por Satélite. Instituto Nacional de Pesquisas Espaciais (INPE), São José dos Campos, São Paulo, Brasil. Disponível em <http://www.obt.inpe.br/ prodes/>, 2007.

BRASIL, MCT. Brazil's Initial National Communication to the United Nations Framework Convention on Climate Change. Ministério de Ciência e Tecnologia (MCT), Brasília, DF, Brasil. 271 pp. 2004.

BRASIL, PROJETO RADAMBASIL. Levantamento dos Recursos Naturais (Parte das Folhas SA.20 Manaus; SA.21 Santarém; SB.19 Juruá; SB.20 Purus; SC.19 Rio Branco; SC.20 Porto Velho). Ministério das Minas e Energia, Rio de Janeiro, Brasil, 1973-1984.

BRASIL, SIVAM/SIPAM. Banco de Dados IBGE - versão 6 (derivado da recuperação dos dados originais do Projeto RADAMBRASIL). Serviço de Vigilância da Amazônia / Serviço de Proteção da Amazônia, Manaus, Amazonas, Brasil, 2004. (4 CDs)

BROWN, S. Estimating biomass and biomass change of tropical forests. FAO Forestry Paper 134, FAO - Food and Agriculture Organization of the United Nations, Roma, Itália. 54 p., 1997.

BROWN, S.; LUGO, A. Aboveground biomass estimates for tropical moist forest of the Brazilian Amazon. Interciencia, v.17, n.1, p.8-18, 1992.

CÂMARA, G. Developments in Land Change Modelling in Amazonia: Governance and Public Policies. Global Land Project, Scientific Steering Committee Meeting, Copenhagen, October 2007. Apresentação powerpoint, 38 p. Disponível em <http://www.dpi.inpe.br/gilberto/present/ camara_glp_oct_2007.ppt>, 2007.

CARVAlHO, G., O.; BARROS, A. C.; MOUTINHO, P.; NEPSTAD, D. Sensitive development could protect Amazonia instead of destroying it. Nature, v.409, p.131, 2001.

CARVALHO, G. O.; NEPSTAD, D.; MCGRATH, D.; DIAZ, M. C. V.; SANTILLI, M.; BARROS, A. C. Frontier expansion in the Amazon: Balancing development and sustainability. Environment, v.44, n.3, p.34-45, 2002.

CATTEANO, A. Deforestation in the Brazilian Amazon: 
comparing the impacts of macroeconomic shocks, land tenure, and technological change. Land Economics, v.77, p.219-240, 2001.

CHOMITZ, K. M.; THOMAS. T. S. Determinants of land use in Amazônia: A fine-scale spatial analysis. American Journal of Agricultural Economics 85, p.1016-1028, 2003.

FEARNSIDE, P. M. Causes of deforestation in the Brazilian Amazon. In: R.F. Dickinson (ed.) The Geophysiology of Amazonia: Vegetation and Climate Interactions. John Wiley \& Sons, New York, E.U.A. p.37-61., 1987.

FEARNSIDE, P. M. Ocupação Humana de Rondônia: Impactos, Limites e Planejamento. Relatórios de Pesquisa No. 5, Conselho Nacional de Desenvolvimento Científico e Tecnológico (CNPq), Brasília, DF, Brasil. 76 p, 1989.

FEARNSIDE, P. M. Forest biomass in Brazilian Amazonia: Comments on the estimate by Brown and Lugo. Interciencia, v.17, n.1, p.19-27, 1992.

FEARNSIDE, P. M. Biomassa das florestas amazônicas brasileiras. In: Anais do Seminário "Emissão x Seqüestro de CO2: Uma Nova Oportunidade de Negócios para o Brasil". Companhia Vale do Rio Doce, Rio de Janeiro, Brasil. p.95124, 1994.

FEARNSIDE, P. M. Amazonian deforestation and global warming: Carbon stocks in vegetation replacing Brazil's Amazon forest. Forest Ecology and Management, v.80, n.1-3, p.21-34, 1996.

FEARNSIDE, P. M. Greenhouse gases from deforestation in Brazilian Amazonia: Net committed emissions. Climatic Change, v.35, n.3, p.321-360, 1997.

FEARNSIDE, P. M. Global warming and tropical land-use change: Greenhouse gas emissions from biomass burning, decomposition and soils in forest conversion, shifting cultivation and secondary vegetation. Climatic Change, v.46, n.1-2, p.115-158, 2000a.

FEARNSIDE, P. M. Greenhouse gas emissions from land-use change in Brazil's Amazon region. p. 231-249 In: R. Lal, J.M. Kimble \& B.A. Stewart (eds.) Global Climate Change and Tropical Ecosystems. Advances in Soil Science. CRC Press, Boca Raton, Florida, E.U.A. 438 p., 2000b.

FEARNSIDE, P. M. Avança Brasil: Environmental and social consequences of Brazil's planned infrastructure in Amazonia. Environmental Management, v.30, n .6, p.748-763, 2002.

FEARNSIDE, P. M. Brazil's Cuiabá-Santarém (BR-163) Highway: The environmental cost of paving a soybean corridor through the Amazon. Environmental Management, v.39, n.5, p. 601-614, 2007.

FEARNSIDE, P. M.; BARBOSA, R. I. Soil carbon changes from conversion of forest to pasture in Brazilian Amazonia. Forest Ecology and Management, v.108, n.1-2, p.147-166, 1998.

FEARNSIDE, P. M.; GRAÇA, P. M. L. A. BR-319: Brazil's
Manaus-Porto Velho Highway and the potential impact of linking the arc of deforestation to central Amazonia. Environmental Management, v.38, n.5, p.705-716, 2006.

FEARNSIDE, P.M.; LAURANCE, W.F. Tropical deforestation and greenhouse gas emissions. Ecological Applications, v.14, n.4, p.982-986, 2004.

FEARNSIDE, P. M.; LEAL JR., N.; FERNANDES, F. M. Rainforest burning and the global carbon budget: biomass, combustion efficiency, and charcoal formation in the Brazilian Amazon. Journal of Geophysical Research 98(D9): 16733-16743, 1993.

FORSTER, P. \& 51 outros.. Changes in atmospheric constituents and in radiative forcing. p. 129-234. In: S. Solomon, D. Qin, M. Manning, Z. Chen, M. Marquis, K.B. Averyt, M. Tignor \& H.L. Miller (eds.). Climate Change 2007: The Physical Science Basis: Contribution of Working Group I to the Fourth Assessment Report of the Intergovernmental Panel on Climate Change. Cambridge University Press, Cambridge, Reino Unido. 996 p., 2007.

HIGUCHI, N.; SANTOS, J. M.; IMANAGA, M.; YOSHIDA, $\mathrm{S}$. Aboveground biomass esimate for Amazonian dense tropical moist forest. Memories of the Faculty of Agriculture (Kagoshima University), v.30, p.43-54, 1994.

KIRBY, K. R.; LAURANCE, W. F.; ALBERNAZ, A. K.; SCHROTH, G.; FEARNSIDE, P. M.; BERGEN, S.; VENTICINQUE, E. M.; DA COSTA, C. The future of deforestation in the Brazilian Amazon. Futures, v.38, p.432453, 2006.

KLINGE, H.; RODRIGUES, W. A. Phytomass estimation in a Central Amazonian rain forest. In: H.E. Young (ed.), IUFRO Biomass Studies. University Press, Maine, E.U.A. p.339-350, 1974.

KOK, K.; FARROW, A.; VELDKAMP, A.; VERBURG, P. H. A method and application of multiscale validation in spatial land use models. Agriculture, Ecosystems and Environment, v.85, p.223-238, 2001.

LAURANCE, W.F.; BERGEN, S.; COCHRANE, M.A.; FEARNSIDE, P.M.; DELAMONICA, P.; D'ANGELO, S.; BARBER, C.; FERNANDES, T. The future of the Amazon. pp. 583-609 In: E. Bermingham, C.W. Dick \& C. Moritz (eds.) Tropical Rainforests: Past, Present and Future. University of Chicago Press, Chicago, Illinois, E.U.A. 1004 p., 2005.

LAURANCE, W.F .; COCHRANE, M. A.; BERGEN, S.; FEARNSIDE, P. M.; DELAMÔNICA, P.; BARBER, C.; D'ANGELO, S.; FERNANDES, T. The future of the Brazilian Amazon. Science, v.291, p.438-439, 2001.

LAURANCE, W. F.; FEARNSIDE, P. M.; LAURANCE, S. G.; DELAMONICA, P.; LOVEJOY, T. E.; RANKIN-DE MERONA, J. M.; CHAMBERS, J. Q.; GASCON, G. 
Relationship between soils and Amazon forest biomass: A landscape-scale study. Forest Ecology and Management, v.118, p.127-138, 1999.

MARGULIS, S. Causas do Desmatamento na Amazônia Brasileira. Banco Mundial, Brasília, DF, Brasil, 2003.

NASCIMENTO, M. T.; BARBOSA, R. I.; VILLELA, D. M; PROCTOR, J. Above-ground biomass changes over an 11year period in an Amazon monodominant forest and two other lowland forests. Plant Ecology, v.192, p.181-191, 2007.

NEPSTAD, D. C.; CAPOBIANCO, J. P.; BARROS, A. C.; CARVAlho, G.; MOUTINHO, P.; LOPES, U.; LEFEBVRE, P. Avança Brasil: Os Custos Ambientais para Amazônia. Instituto de Pesquisa Ambiental da Amazônia (IPAM), Belém, Pará, Brasil. 24 p. Disponível em $<$ http:// www.ipam.org.br/avanca/politicas.htm>, 2000.

NEPSTAD, D.; CARVALHO, G.; BARROS, A. C.; ALENCAR, A.; CAPOBIANCO, J. P.; BISHOP, J.; MOUTINHO, P.; LEFEBVRE, P.; SILVA, JR., U. L.; PRINS, E. Road paving, fire regime feedbacks, and the future of Amazon forests. Forest Ecology and Management, v.154, n.3, p.395-407, 2001.

NOGUEIRA, E.M.; FEARNSIDE, P.M.; NELSON, B.W.; BARBOSA, R.I.; KEIZER, E.W.H. Estimates of forest biomass in the Brazilian Amazon: New allometric equations and adjustments to biomass from wood-volume inventories. Forest Ecology and Management v.256, n.11, p.1853-1857, 2008.

NOGUEIRA, E. M.; FEARNSIDE, P. M.; NELSON, B. W.; FRANÇA, M. B. Wood density in forests of Brazil's 'arc of deforestation': Implications for biomass and flux of carbon from land-use change in Amazonia. Forest Ecology and Management, v.248, n.3, p.119-135, 2007.

NOGUEIRA, E. M.; NELSON, B. W.; FEARNSIDE, P. M. Wood density in dense forest in Central Amazonia, Brazil. Forest Ecology and Management, v.208, n.1-3, p.261-286, 2005.

NOGUEIRA, E. M.; NELSON, B. W.; FEARNSIDE, P. M. Volume and biomass of trees in central Amazonia: Influence of irregularly shaped and hollow trunks. Forest Ecology and Management, v.227, n.1-2, p.14-21, 2006.

PFAFF, A.; ROBALINO, J.; WALKER, R.; ALDRICH, S.; CALDAS, M.; REIS, E.; PERZ, S.; BOHRER, C.; ARIMA, E.; LAURANCE, W.; KIRBY, K. Road investments, spatial spillovers, and deforestation in the Brazilian Amazon. Journal of Regional Science v.47, p.109-123, 2007.

REDE TEMÁTICA GEOMA. Análises preliminares dos efeitos espaciais de áreas protegidas na ALAP da BR 319. Grupo Permanente de Trabalho Interministerial sobre Desmatamento na Amazônia, Casa Civil da Presidência da
República, Brasília, DF, Brasil, 2006.

REIS, E. J. \& R. GUZMÁN. An Econometric model of Amazon deforestation. In: Brown, K. \& Pearce, D. W. (eds.) The Causes of Tropical Deforestation: The Economic and Statistical Analysis of Factors Giving Rise to the Loss of Tropical Forests. University College London Press, London, Reino Unido, p.172-191, 1994.

REIS, E. J.; MARGULIS, S. Options for slowing Amazon jungle clearing. In: R. Dornbusch \& J. Poterbar (eds.) Economic Policy Responses to Global warming. MIT Press, Cambridge, Massachusetts, E.U.A., p.335-375, 1991.

REIS, E. J.; WEINHOLD, D. Land use and transportation costs in the Brazilian Amazon. University of Wisconsin-Madison, Department of Agriculture \& Applied Economics Staff Paper No. 467. Madison, Wisconsin, E.U.A. 31 p., 2004.

RODRIGUES, H. O.; SOARES-FILHO, B. S.; COSTA, W. L. S. Dinamica EGO, uma plataforma para modelagem de sistemas ambientais. In: Simpósio Brasileiro de Sensoriamento Remoto, 13. Instituto Nacional de Pesquisas Espaciais (INPE), São José dos Campos, São Paulo, Brazil, 2007.

SCHIMEL, D. \& 75 outros. Radiative forcing of climate change. p. 65-131. In: J.T. Houghton, L.G. Meira Filho, B.A. Callander, N. Harris, A. Kattenberg \& K. Maskell (eds.). Climate Change 1995: The Science of Climate Change. Cambridge University Press, Cambridge, Reino Unido, 1996. SOARES-FILHO, B. S. SIMAMAZONIA. Centro de Sensoriamento Remoto (CSR), Universidade Federal de Minas Gerais (UFMG), Belo Horizonte, Minas Gerais, Brasil. Disponível em <http://www.csr.ufmg.br/ simamazonia>, 2004.

SOARES-FILHO, B. S.; ALENCAR, A. A.; NEPSTAD, D. C.; CERQUEIRA, G. C.; DIAZ, M. DEL C. V.; RIVERO, S.; SOLÓRZANO, L.; VOLL, E. Simulating the response of land-cover changes to road paving and governance along a major Amazon highway: The Santarém-Cuiabá corridor. Global Change Biology, v.10, n.5, p.745-764, 2004.

SOARES -FILHO, B. S.; CERQUEIRA, G. C.; PENNACHIN, C. L. DINAMICA-A stochastic cellular automata model designed to simulate the landscape dynamics in an Amazonian colonization frontier. Ecological Modelling, v.154, p.217-235, 2002.

SOARES-FILHO, B. S.; CORRADI FILHO, L.; CERQUEIRA, G. C.; ARAÚJO, W. L. Simulating the spatial patterns of change through the use of the DINAMICA model. Anais XI SBSR, Belo Horizonte, Brasil. Instituto Nacional de Pesquisas Espaciais (INPE), São José dos Campos, São Paulo, Brasil. p.721-728, 2003.

SOARES-FILHO, B.; DIETZSCH, L.. Reduction of Carbon Emissions Associated with Deforestation in Brazil: The Role 
of the Amazon Region Protected Areas Program (ARPA). World Wide Fund for Nature (WWF), Brasilia, Brazil. 32 p., 2008.

SOARES-FILHO, B. S.; NEPSTAD, D. C.; CURRAN, L.; CERQUEIRA, G. C.; GARCIA, R. A.; RAMOS, C. A.; LEFEBVRE, P.; SCHLESINGER, P.; VOLL, E.; McGRATH, D. Cenários de desmatamento para Amazônia. Estudos Avançados, v.19, n.54, p.138-152, 2005.

SOARES-FILHO, B. S.; NEPSTAD, D. C.; CURRAN, L. M.; CERQUEIRA, G. C.; GARCIA, R. A.; RAMOS, C. A.; VOLL, E.; MCDONALD, A.; LEFEBVRE, P.; SCHLESINGER, P. Modelling conservation in the Amazon basin. Nature, v.440, p.520-523, 2006.

SOUZA Jr., C.; BRANDÃO Jr., A.; ANDERSON, A.; VERÍSSIMO, A. Avanço das estradas endógenas na Amazônia. O Estado da Amazônia, Instituto do Homem e Meio Ambiente na Amazônia (IMAZON), Belém, Pará, Brasil. 2 p. Disponível em <http://www.imazon.org.br/ downloads/download.asp?id=234>, 2005.

VELDKAMP, A.; VERBURG, P.H.; KOK, K.; De KONING, G.H.J.; PRIESSE, J.; BERGSMA, A.R. The need for scale sensitive approaches in spatially explicit land use change modeling. Environmental Modeling and Assessment, v.6c, p.111-121, 2001.

VENTANA SYSTEMS INC. Vensim from Ventana Systems Inc., Belmont, Massachusetts, E.U.A. Disponível em $<\mathrm{http}: / /$ www.vensim.com/>, 2007.

VERBURG, P. H.; SOEPBOER, W.; VELDKAMP, A.; LIMPIADA, R.; ESPALDON, V.; MASTURA, S. S. A. Modeling the spatial dynamics of regional land use: the CLUE-S model. Environmental Management, v.30, n.3, p.391-405, 2002. 